\title{
HELIUM RESEARCH IN SUPPORT OF SUPERCONDUCTING POWER TRANSMISSION
}

\section{ANNUAL REPORT \\ October 1979 - September 1980}

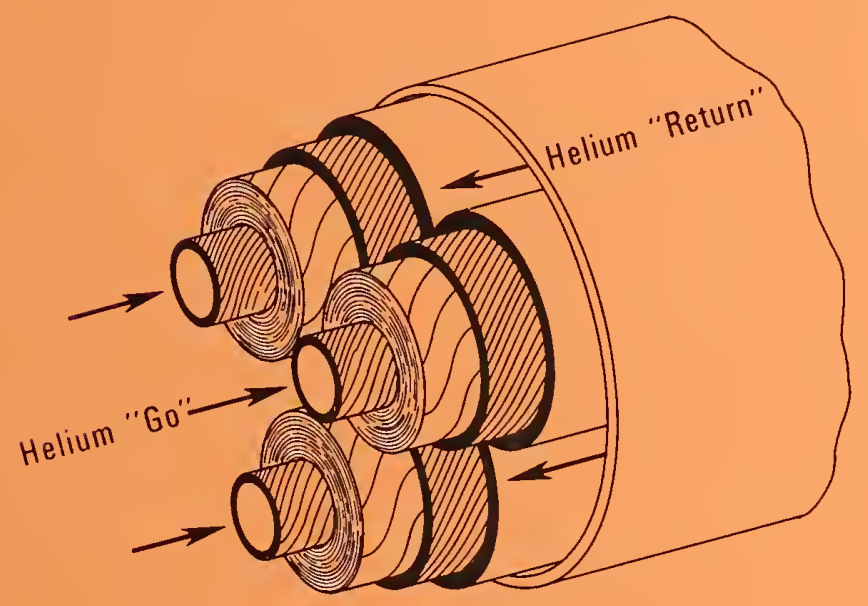

PREPARED BY

Thermophysical Properties Division

Narional Bureau of Srandards

QC Boulder, Colorado 80303
PREPARED FOR

Brookhaven Narional Laborarory

Power Transmission Projecr

Upron, New York 11973

100

.456

$81-1649$

1 y81

C. 2 



\title{
HELIUM RESEARCH IN SUPPORT OF SUPERCONDUCTING POWER TRANSMISSION
}

\author{
Annual Report for the period \\ October 1, 1979 - September 30, 1980
}

\author{
PREPARED BY \\ Thermophysical Properties Division \\ Center for Chemical Engineering \\ National Bureau of Standards \\ Boulder, Colorado 80303
}

D. E. Daney, Editor

Contract No. $433475-5$

PREPARED FOR

Brookhaven Narional Laboratory

Power Transmission Project

Upron, New York 11973

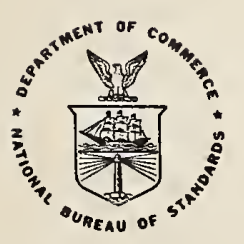

U.S. DEPARTMENT OF COMMERCE, Malcolm Baldrige, Secrerary

NATIONAL BUREAU OF STANDARDS, Ernest Ambler Direcror 



\section{CONTENTS}

PAGE

1.0 COOL-DOWN STRATEGIES

1.1 Introduction 1

1.2 Description of the Transmission Line and Refrigeration System 3

1.3 Computational Method 8

$\begin{array}{ll}\text { 1.3.0 Governing Equations } & 8\end{array}$

1.3.1 Material Properties 9

1.3.2 Numerical Method 9

$\begin{array}{ll}1.3 .3 \text { Boundary Conditions } & 10\end{array}$

$\begin{array}{lll}1.4 & \text { Results and Discussion } & 10\end{array}$

1.5 Fast Cool-Down Prototype 19

$\begin{array}{lll}1.6 & \text { Summary } & 19\end{array}$

1.7 References 22

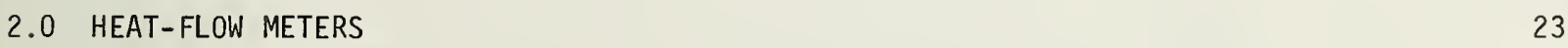

2.1 Introduction 23

2.2 Pipe Section and Meter Assembly 24

2.3 Field Burial, Pipe Assembly 24

2.4 Test Sequence $\quad 28$

2.5 Test Results 28

2.6 Field Performance of the "A" and "B" Pair of Heat-Flow Meters 29

2.7 Field Performance of the "C" Pair of Meters 32

2.8 Summation of the emf from the "C" Pair of Meters 32

2.9 Time Response of the Heat-Flow Meters $\quad 35$

2.10 Comparison of a Meter Thermocouple to an Earth Thermocouple During a Snow-Melt Period $\quad 35$

2.11 Performance of the Heat-Flow Meters Above Ground 35

2.11 .1 Non-Shaded $\quad 35$

2.11 .2 Shaded Cover 38

2.12 Conclusions 38

2.13 References $\quad 39$ 


\section{ABSTRACT}

During FY 80, the NBS Thermophysical Properties Division program of research for superconducting power transmission line (SPTL) development focused on two tasks:

1) Development of SPTL cool-down strategies.

2) Experimental evaluation of thermal flux meters as a possible technique for determining enclosure heat leak.

In developing SPTL cool-down strategies, we used a computer code (previously developed at NBS) to explore c001-down times for a wide variety of realistic boundary conditions. cool-down times of 10 days are feasible with only minor modification to previously proposed refrigeration systems if cooling channel lengths are reduced to two thirds or one half those dictated by steady-state considerations.

Evaluation of thermal flux meters was concluded. Below ground field tests revealed large effects due to seasonal variation in the soil heat flux. These effects can be largely cancelled by algebraic addition of the signals from a pair of horizontally opposed sensors. A brief above ground field evaluation indicated that diurnal variations in the heat flux completely mask heat fluxes typical of the anticipated enclosure heat flux.

Key words: Cable cool-down; cool-down; heat flux meters; helium; superconducting power transmission. 


\subsection{COOL-DOWN STRATEGIES}

(D. E. Daney)

\subsection{Introduction}

Cool-down of superconducting power transmission lines (SPTL's) has been the subject of investigation at NBS for the past several years. Analytical, experimental, and numerical Inodeling of SPTL cool-down have been reported previously $[1,2,3]$. The subject of this report is application of the numerical model developed at NBS by Jones [2, 4] to perfect $a$ rapid cool-down strategy for a particular SPTL application. The application chosen is for a P'niladelphia Electric Company (PECo)* hypothetical 10,000 MVA transmission line between a power station on the Susquehanna River and Philadelphia - a distance of $106 \mathrm{~km}$. This 3-phase ac, $230 \mathrm{kV} \mathrm{SPTL}$ has previously been the subject of an extensive economic and technological evaluation comparing a number of different power transmission systems [5].

Rapid cool-down is essential to a practical superconducting power transmission line since total down-time for repairs includes both the cool-down and warm-up times. Although the more rapid the better, a week to ten day cool-down is taken as a reasonable compromise between short repair down-times and the design modifications required to achieve them.

The PECo, SPTL cooling arrangenent is based on one proposed at Brookhaven National Laboratory (BNL). The BNL design $[6,7]$, figure 1.1 , uses a counter-flow arrangement wherein supercritical helium flows down the hollow core of the cable, is expanded to a lower pressure (and temperature) at the far end, and then is returned in the space between the cable and the cryogenic enclosure. Although this counter-flow arrangement eliminates the expense of a separate insulated helium return line, it poses cool-down difficulties. The cooling channel is, in effect, a rather efficient counter-flow heat exchanger, and at the limit of perfect heat exchange a counter-flow heat exchange will never cool down. This situation arises because as the heat exchange effectiveness increases, the temperature difference between the go and return streams (which determines the rate of refrigeration) decreases. Fortunately, there are several practical ways to alleviate this situation. Their development requiras a fundamental understanding of the problem.

Preliminary calculations for this PECo SPTL gave a cool-down of 104 days. Clearly significant changes were required if acceptable cool-down times of a week to ten days were to be achieved.

The general approach to be taken was indicated by our previous analytical work for the counter-flow arrangement which gave the expression for cool-down time, $t_{c d}$, as:

$$
t_{c d} \sim\left(\frac{l}{m}\right)^{2}
$$

\footnotetext{
FThe hypothetical transmission line chosen for the purpose of the study was established by the sponsor. The use of this hypothetical case in no way constitutes an endorsement by the National Bureau of Standards of the described transmission line or the Philadelphia Electric Company PECo)."
} 


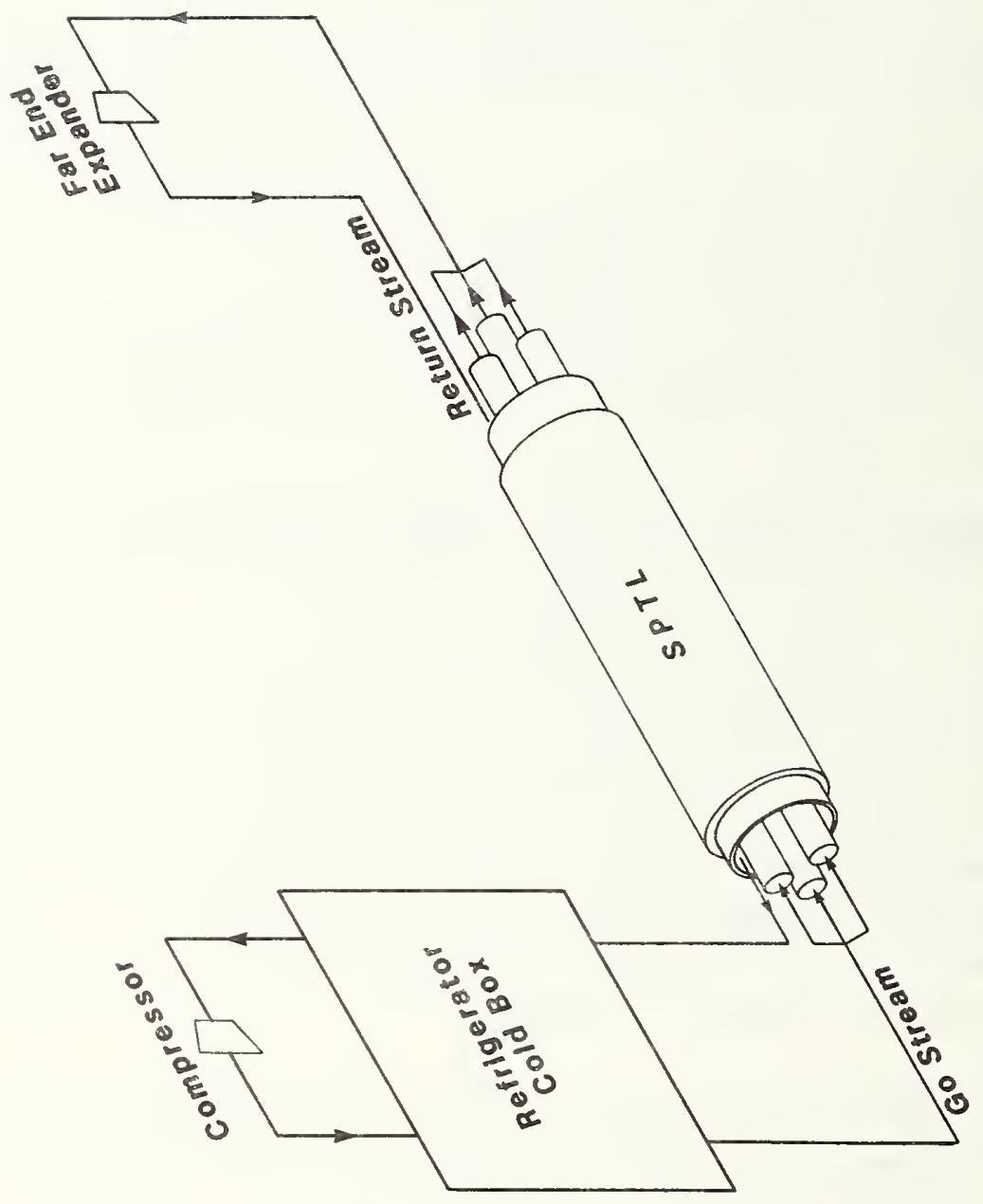

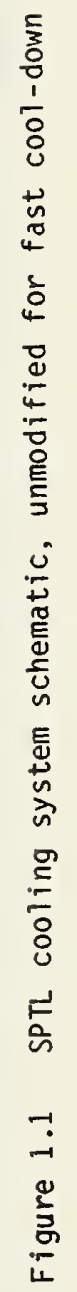


where $\ell$ is the cooling channel length and $m$ is the mass flow rate. When the flow is limited by the cooling channel pressure drop the cool-down time expression becomes:

$$
t_{c d} \sim \ell^{3}
$$

For cooling both ends, the effective length is one-half that for cooling from one end only. Our numerical studies support the same general conclusions, although the exponents differ slightly. Minimum cool-down times thus require:

a. Minumum economically practical cooling channel length,

b. Maximum refrigeration possible (minimum practical temperature) applied to both ends, and

c. Maximum driving pressure (i.e., maximum flow).

By appropriate application of these principles we reduced the calculated cool-down time to the required 10 days. Among the changes in design that are required is a reduction in cooling channel length from $28 \mathrm{~km}$ to $19 \mathrm{~km}$ or $14 \mathrm{~km}$.

During the course of the study, 24 cases were calculated to evaluate the effect of length, pressure drop, far-end expander, far-end liquid nitrogen precooling, near-end refrigerator configurations, and heat leak for the counterflow cool-down arrangement. Cocurrent cool-down and counter-flow warm-up were also studied.

\subsection{Description of the Transmission Line and Refrigeration System}

Refrigeration for the Philadelphia Electric Company (PECo) hypothetical superconducting power transmission line (SPTL) is supplied by the arrangement in figure 1.2. Two refrigeration stations plus three far-end turboexpander stations cool the entire $106 \mathrm{~km}$ length, so that the length of a single cooling channel is $26.6 \mathrm{~km}$. Because it may not be convenient to position the stations at the exact intervals shown, we assume a $28 \mathrm{~km}$ cooling channel length as a base case. Closer spacings considered in the cool-down calculations are $18.7 \mathrm{~km}(3$ refrigeration stations), and $14 \mathrm{~km}$ (4 refrigeration stations).

The refrigerator uses the hybrid Claude-Brayton cycle shown in figure 1.3, which gives typical steady state operating conditions. Some cool-down calculations assume a 20 bar gostream inlet rather than the 15 bar given in the figure.

Although the far-end refrigeration supplied by the far-end turboexpander (figure 1.1) is adequate for steady state operation, it is inadequate for rapid cool-down. A simple and inexpensive means of improving the far-end refrigeration is addition of a far-end liquid nitrogen precooler as shown in figure 1.4. With this arrangement, the return stream may be cooled to $80 \mathrm{~K}$ by the $\mathrm{LN}_{2}$ bath and returned directly to the SPTL or it may also pass through the turboexpander before returning. The lowest far-end return-stream temperature is, of course, achieved when both the turbine and the $\mathrm{LN}_{2}$ bath are used. However, the mass flow is greater if the turbine is bypassed since the pressure drop that was previously taken up across the turbine is now used to drive the flow.

The cable construction and dimensions assumed for the cool-down calculations are given in figure 1.5 and table 1.1 . 


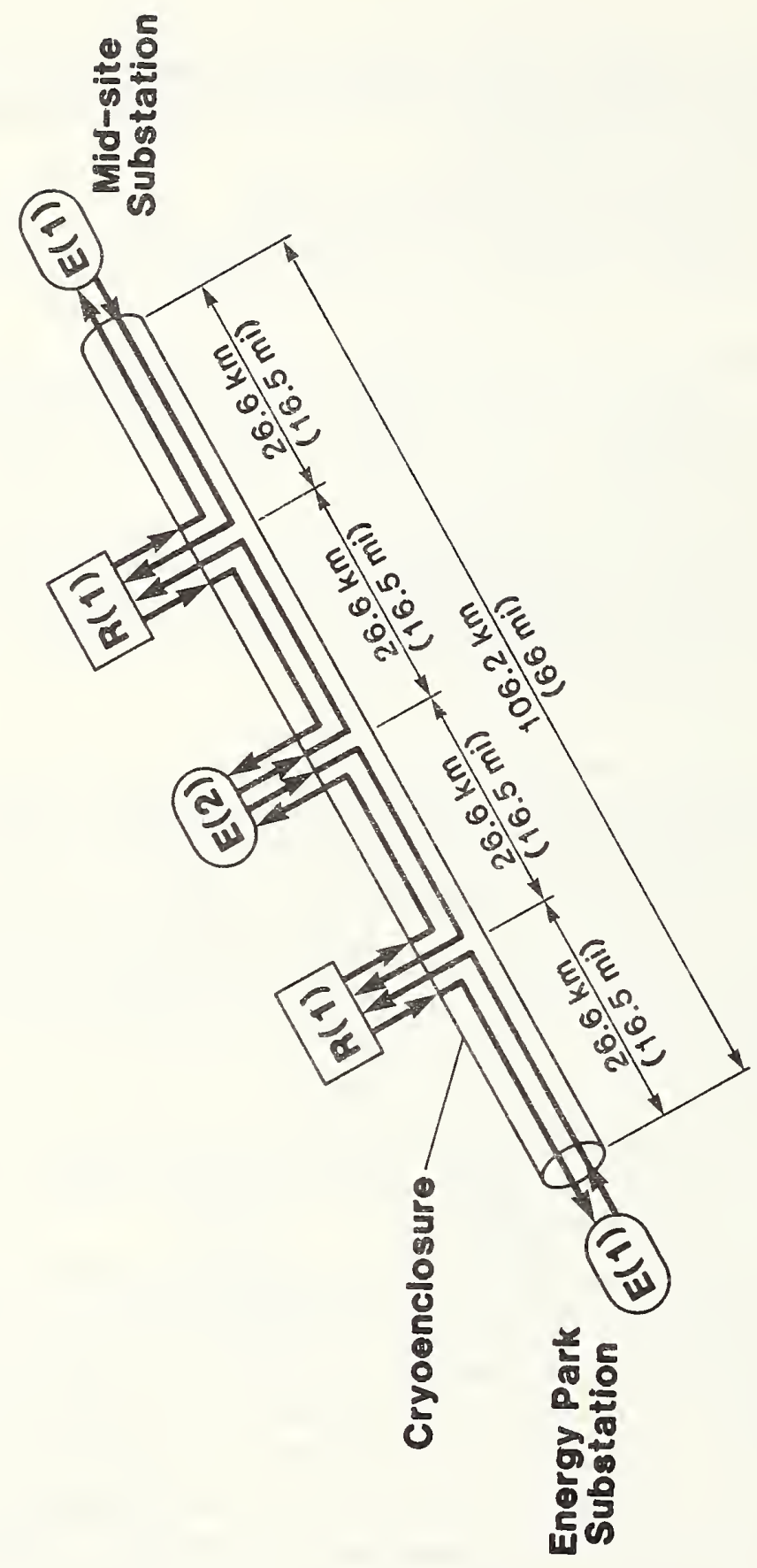

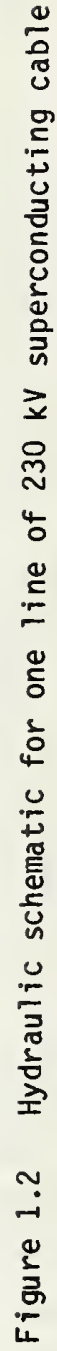




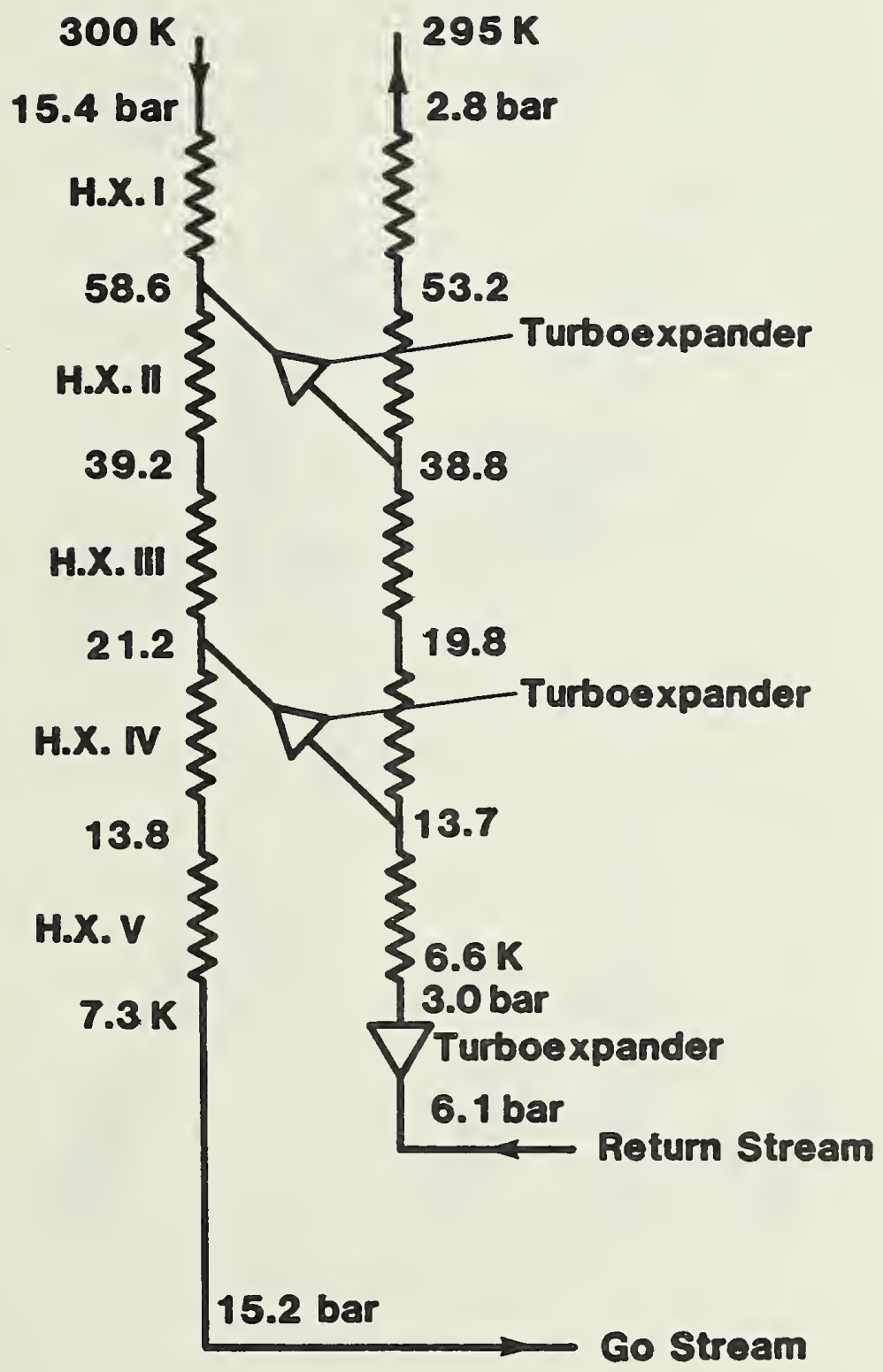

Figure 1.3 Refrigerator schematic 


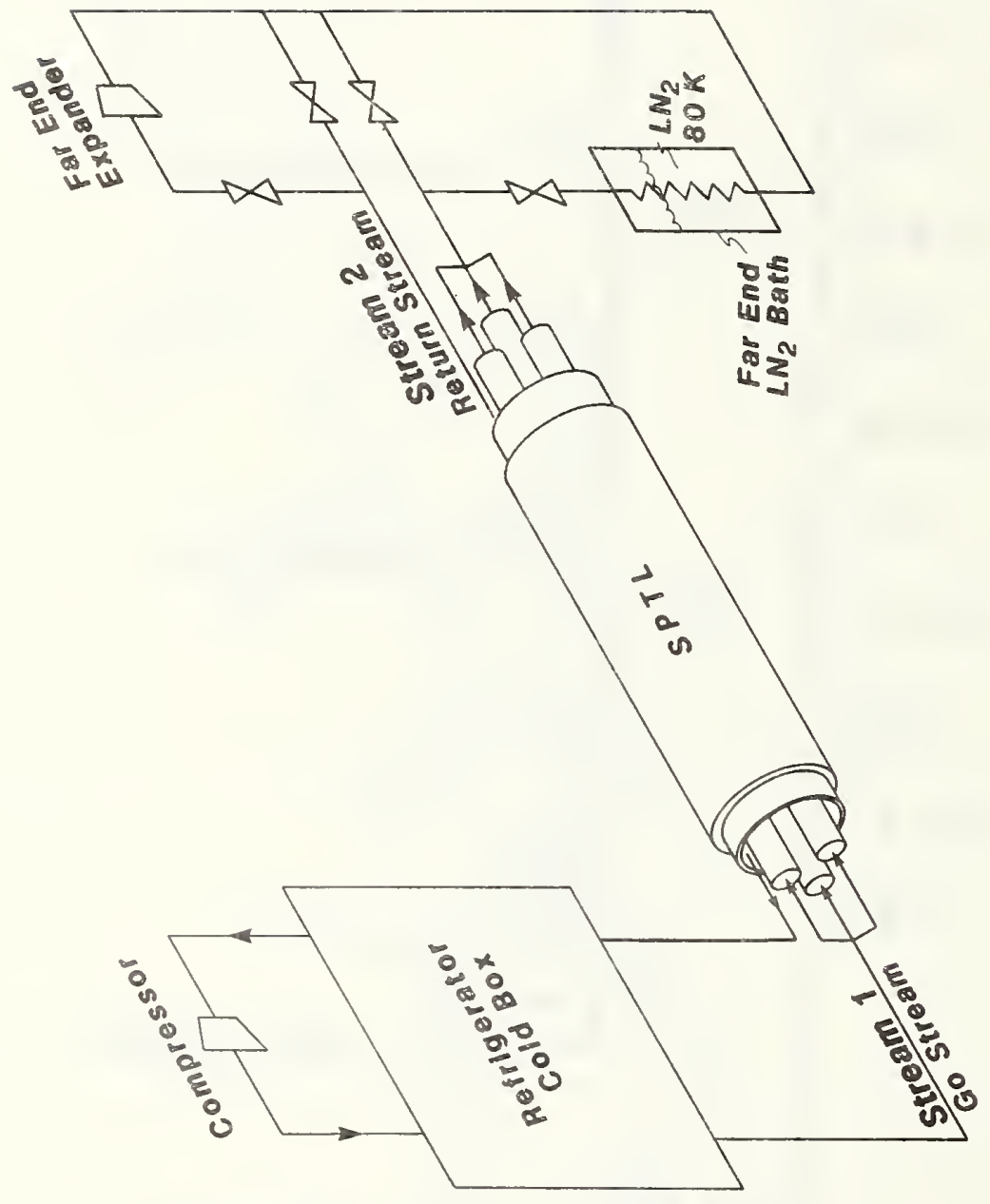

वे 


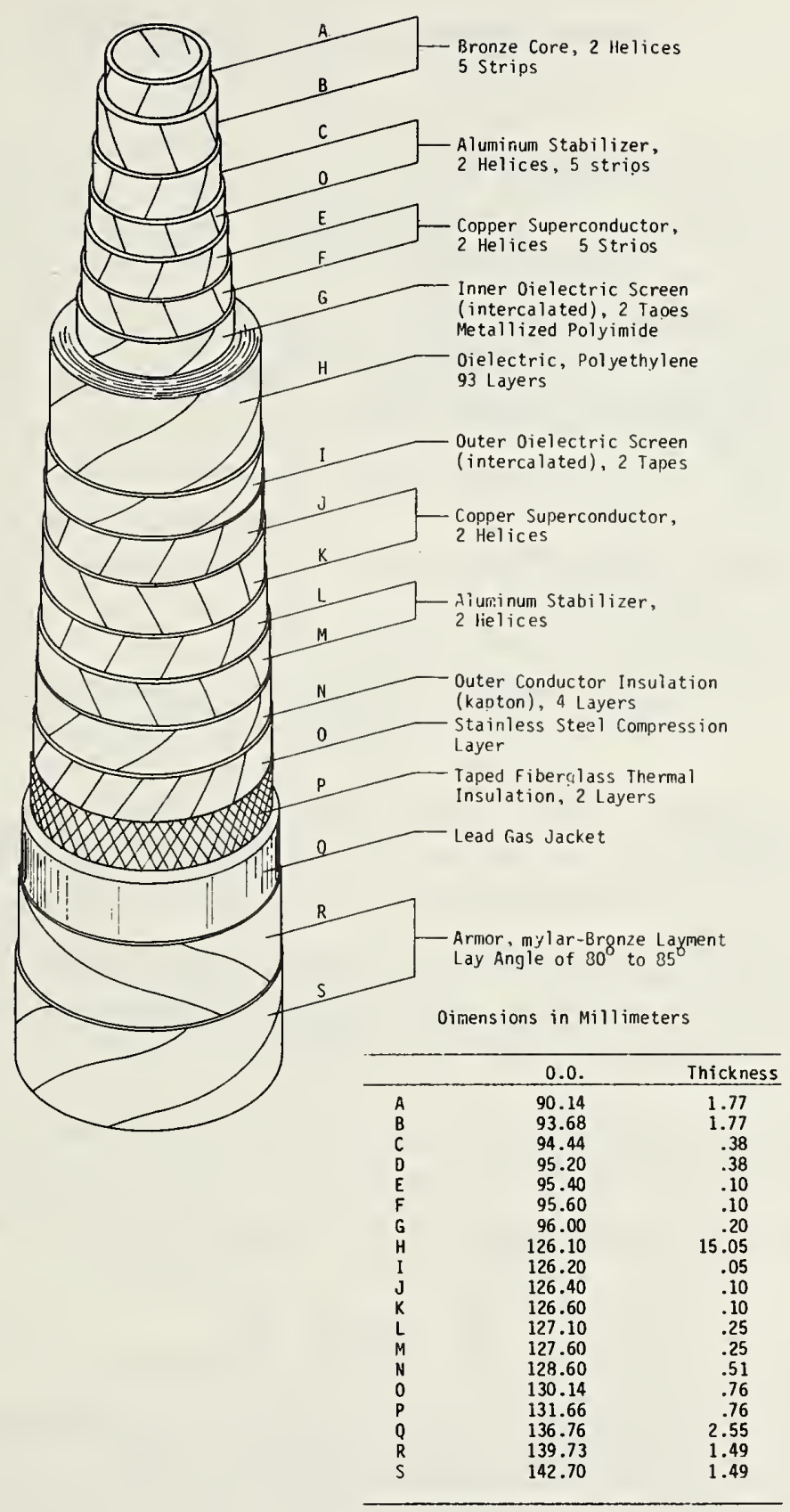

Figure 1.5 Cable cross section, cut back view 
Table 1.1

Summary of Cable and Enclosure Details

CABLE

Core inside diameter ( $\mathrm{mm}$ )

90.1

Insulation inside diameter (mm)

95.6

Insulation outside diameter (mm)

126.2

Cable outside diameter ( $m$ m)

142.7

Go stream flow area ( 3 cables) $\left(\mathrm{m}^{2}\right)$

$17.7(10)^{-3}$

Weight/meter ( 3 cables) $(\mathrm{kg} / \mathrm{m})$

121.7

\section{ENCLOSURE}

Inside diameter (mm)

340.0

Wall thickness (mm)

2.2

Steady state-heat leak (W/m)

0.45

Cooling channel length (base case) (km)

28.0

\subsection{Computational Method}

\subsubsection{Governing Equations}

Because the computational method has previously been described in detail [2, 4] we give only a brief outline here. For each of the helium streams the one-dimensional continuity, energy, and rmomentum equations are:

$$
\begin{aligned}
& \frac{\partial \rho}{\partial t}+\frac{V \partial \rho}{\partial x}+\frac{\rho \partial V}{\partial x}=0 \\
& \frac{\rho \partial}{\partial t}\left(\frac{H+V^{2}}{2}\right)+\frac{\rho V \partial}{\partial x}\left(\frac{H+V 2}{2}+\Phi\right)=\frac{\partial P}{\partial t}+\frac{\Lambda}{\partial} \\
& \frac{\partial V}{\partial t}+\frac{V \partial V}{\partial x}=-\frac{1}{\rho} \quad \frac{\partial P}{\partial x}-\frac{f V|V| p}{2 a}-\frac{\partial \Phi}{\partial x}
\end{aligned}
$$

Here, the density $\rho$ is regarded as a known function of $P$ and $H$, the potential energy $\Phi^{\prime}$ is a known function of $x$, accounting for changes in elevation, and $\Lambda$ is the heat transfer to the fluid stream per unit length. The friction factor $f$ could be calculated from the local fluid Reynolds number or, as we have done here, set equal to a constant for typical conditions. $p$ and a are wetted perimeter and cross-sectional area of the appropriate helium channel.

We can arrive at a set of equations in which only one time derivative $\frac{\partial P}{\partial t}$, $\frac{\partial H}{\partial t}$ or $\frac{\partial V}{\partial t}$ occurs by taking linear combinations of (1.1), (1.2), and 1.3), and by use of thermodynamic identities. This form is required by the numerical method we use. By retaining $P$ and $H$ as thermodynamic variables rather than $P$ and $T$ we avoid thermodynamic derivatives such as specific heat which are sharply peaked at the transposed critical temperature. The resulting equations are: 


$$
\begin{aligned}
& \frac{\partial P}{\partial t}=-\frac{V \partial P}{\partial x}-\rho c^{2} \frac{\partial V}{\partial x}+\Phi\left[\frac{\Lambda}{a}+\frac{\rho V^{2} f|V| p}{2 a}\right] \\
& \frac{\partial H}{\partial t}=-\frac{V \partial H}{\partial x}-c^{2} \frac{\partial V}{\partial x}+\frac{1+\Phi}{\rho}\left[\frac{\Lambda}{a}+\frac{\rho V^{2} f|V| p}{2 a}\right] \\
& \frac{\partial V}{\partial t}=-\frac{1}{\rho} \frac{\partial P}{\partial x}-\frac{V \partial V}{\partial x}-f \frac{V|V| p}{2 a}-\frac{\partial \Phi^{\prime}}{\partial x}
\end{aligned}
$$

where $\Phi=\frac{\rho}{T}\left(\frac{\partial T}{\partial \rho}\right)$ the Gruneisen parameter and $c^{2}=\left(\frac{\partial P}{\partial \rho}\right)$, where $c$ is the acoustic velocity.

There is on such set of three equations for each ${ }^{5}$ fluid stream and the independent variables and coefficients can be subscripted 1 and 2 for the inner and outer streams respectively. They are coupled to appropriate energy equations for the cable and outer pipe through the heat transfer terms $\Lambda_{1}$ and $\Lambda_{2}$.

For the cable composite the appropriate one-dimensional energy conservation equation is of the form

$$
\sum \rho_{i} C_{i} a_{i} \frac{\partial T_{c a b l e}}{\partial t}=\sum \frac{\partial}{\partial x}\left(k_{i} a_{i} \frac{\partial T_{c a b l e}}{\partial x}\right)-\Lambda_{1}^{c a b l e}-\Lambda_{2}^{c a b l e}
$$

where $\rho_{j}, c_{i}, k_{j}$, and $a_{i}$ are the density, specific heat, thermal conductivity and cross sectional area of the ith cable component. It is easy to show that the heat conduction term on the right hand side is quite negligible in all cases considered. A similar equation can be written for the outer pipe:

$$
(p C a)_{\text {pipe }}\left(\frac{\partial T}{\partial t}\right) \text { pipe }=\frac{\partial}{\partial x}\left[(k a) \text { pipe } \frac{\partial T}{\partial x}\right]+Q-\Lambda_{2}{ }^{p i p e}
$$

where again for practical purposes the first term on the right hand side can be neglected. $Q$ is the radiant heat leakage per unit length to the outer pipe from the ambient temperature vacuum pipe through a multilayer insulation which is assumed to cover the outer pipe.

\subsubsection{Material Properties}

In eqs. 1.4 through 1.6 the coefficients $\rho, C^{2}, \Phi$, and, through $\Lambda, T$ are regarded or known functions of the dependent variables $P$ and $H$. For fast computer evaluation it was found advantageous to express these as polynomials fitted to the more exact equation of state of McCarty [8]. In eqs 1.7 and 1.8 the specific heats $C_{j}$ of the cable components were fitted to selected data from the literature.

\subsubsection{Numerical Method}

Integration of the set of eight partial differential equations was accomplished using the computer program PDECOL developed by Madsen and Sincovec [9]. This program is based on the method of lines and uses finite element collocation for the discretization of the spatial variable. Using piecewise polynomials for the trial function space, the procedure reduces the system to a set of first order ordinary differential equations with time as the independent variable. The program then uses established procedures for stiff systems to 
perform the time integration. PDECOL has been tested by its authors and found to be up to an order of magnitude faster than a similar finite difference technique for the same accuracy.

Since PDECOL was designed for non-linear partial differential equations it was relatively straightforward to introduce a properties subroutine to calculate the properties discussed above for every new value of the solution vector and supply the solution-dependent coefficients in the differential equation. This adds significantly to the run time, but the increase was still less than $10 \%$ in our computations.

\subsubsection{Boundary Conditions}

In the counter-flow cool-down calculations the flow is governed by the pressure drop which gives the boundary conditions

$$
\begin{aligned}
x & =0 \\
P_{1} & =\text { constant } \\
P_{2} & =\text { constant } \\
\text { at } x & =L \\
P_{1} & =\text { constant } \\
P_{1} A_{1} V_{2} & =\rho_{2} A_{2} V_{2} \text { (continuity) }
\end{aligned}
$$

where subscript 1 refers to the go stream and 2 refers to the return stream.

For constant temperature refrigeration the enthalpy boundary condition is $H=H(t)$ where $H(t)$ is a linear or exponential decay to a fixed value. The far-end expander gives $H_{2}=H_{2}\left(P_{1}, \gamma, P_{2}, H_{1}\right)$ and a more realistic near-end refrigerator gives $H_{1}=H_{1}\left(P_{2}, H_{2}\right)$.

In co-current cool-down the flow is rimited by the available mass flow and the boundary conditions becone

$$
\text { at } \begin{aligned}
x & =0 \\
(\rho A V)_{1} & =\text { constant } \\
(\rho A V)_{2} & =\text { constant } \\
\text { at } x & =L \\
p_{1} & =\text { constant } \\
p_{2} & =\text { constant }
\end{aligned}
$$

Specification of both pressure and flow at the same end is numerically unstable, and physically impossible without feed-back control at the far-end.

\subsection{Resuits and Discussion}

The effect of length, pressure drop, far-end expander, liquid nitrogen precooling, precooling temperature, heat leák, and refrigerator configuration were evaluated in twenty- 
four cool-down calculations for the PECo SPTL. Table 1.2 summarizes these results. One warm-up calculation (run 1015) is also included.

The shortest cool-down time, 3.8 days, (run 519) is given by the co-current arrangement wherein streams 1 and 2 both flow in the same direction. Increasing the flow to $1.5 \mathrm{~kg} / \mathrm{s}$ would give a 2.5 day cool-down. Although the co-current arrangement gives the fastest cooldown, it requires a separate return line and a refrigerator much larger than that required for steady-state operation. Thus it is not an economically attractive method of SPTL CDOTdown.

The next fastest conl-down time is 7.9 days for a $14 \mathrm{~km}$ length (run 225) assuming cooling from both ends with refrigerators supplying a constant $10 \mathrm{~K}$ helium stream. Although constant temperature refrigerators at both ends are not particularly practical, this case gives the minimum cool-down time for the counterflow arrangement.

In considering the far-end arrangement, the preferred mode of operation (referring to figure 1.4 ) is to bypass the turboexpander and use all the available pressure drop to increase the flow rate. When the go-stream exit temperature is greater than the liquid nitrogen bati temperature, the flow is passed through the $L N_{2}$ bath before returning. After the go-stream exit temperature falls below the batin temperature tine go-stream connects directly to the return stream inlet, bypassing the $L N_{2}$ pot. A reduction in cool-down time of about $10 \%$ can be achieved by pumping the far-end $\mathrm{LN}_{2}$ bath to $65 \mathrm{~K}$, but the added coinplexity and capital cost appear undesirable.

Although a constant temperature near-end refrigerator is a convenient device for comparing the effect of length, pressure drop, heat leak, and various far-end arrangements, it is not a realistic model of actual refrigerator behavior. In practice, the refrigerator output temperature (go-stream inlet temperature) depends on the input temperature (returnstream exit temperature). If we assume that the refrigerator passes through a series of quasi-steady states during cool-down (i.e., that the refrigerator time constant is short compared to the transmission line time constant) then the go-stream inlet temperature may be calculated in a fairly straightforward manner for a particular refrigeration scheme. With no modification to the proposed refrigerator (figure 1.3) we obtained a 28 day cool-down for a $18.7 \mathrm{~km}$ length (run 605) compared to 12.2 days for a near-end constant temperature refrigerator (run 506). In this case, the go-stream inlet is cooled to the temperature of the turboexpander discharge.

Two schemes which provide much faster c001-down are given in figure 1.6. Both schemes are modified versions of the steady-state refrigeration scheme shown in figure 1.3. Both schemes use liquid nitrogen precooling. The refrigerator output temperature (go-stream inlet temperature) for these schemes is given as a function of input temperature (returnstream exit temperature) in figure 1.7 .

In Scheme $A$, (figure 1.6 ) the return stream exit is cooled to $80 \mathrm{~K}$ by the $\mathrm{LN}_{2}$ bath if $\mathrm{T}_{2}$ is greater than $80 \mathrm{~K}$. If $\mathrm{T}_{2}$ is less than $80 \mathrm{~K}$, the return stream goes directly to the expander. In both cases the gas is expanded from $6 \mathrm{~atm}$ to $3 \mathrm{~atm}$ to give temperature $T_{d}$. We assume that the go-stream enters the heat exchanger at temperature $\mathrm{T}_{\mathrm{a}}=2 \mathrm{~T}_{2}$ or that 
Run 1015, warm-up

Near-end, $300 \mathrm{~K}$ supply

Far-end, $300 \mathrm{~K}$ heater

$P_{1}=15.1-6.8$ bar

$P_{2}^{1}=3.0-6.9$ bar

Lèngth $=14 \mathrm{~km}$

Warm-up time $=23$ days to $257 \mathrm{~K}$ at midpoint

Run 724

Near-end, refrigerator Scheme $B$

Far-end, $80 \mathrm{~K} \mathrm{LN}$ cooling

$P_{1}=15.2-6.8$ bar

$p^{1}=3.0-6.9$ bar

Lêngth $=18.7 \mathrm{~km}$

Cool-down time $=19.1$ days

Run $627 \mathrm{~b}$

Near-end, refrigerator Scheme. B

Far-end, $80 \mathrm{~K} \mathrm{LN}$, cooling

$P_{1}=20.3-8.8$ bar

$P_{2}^{1}=3.0-8.8$ bar

Lêngth $=18.7 \mathrm{~km}$

Cool-down time $=11.6$

Run 605

Near-end, turboexpander on?y

Far-end, $80 \mathrm{~K} \mathrm{LN}_{2}$ cooling

$P_{1}=20.3-10.6^{2}$ bar

$P_{2}^{1}=6.1-9.9$ bar

Lêngth $=18.7 \mathrm{~km}$

Cool-down time $=28.4$ days

Run 528

Heat leak, linear function of temperature

Near-end, $10 \mathrm{~K}$ refrigerator

Far-end, turboexpander with $80 \mathrm{~K} \mathrm{LN}_{2}$ precooling

$P_{2}=20.3-10.6$ bar

$P_{2}^{l}=6.1-9.9$ bar

Lêngth $=18.7 \mathrm{~km}$

Cool-down time $=12.2$ days

Run 506

Near-end, $10 \mathrm{~K}$ refrigerator

Far-end, turboexpander with $80 \mathrm{~K} \mathrm{LN}_{2}$ precooling

$P_{1}=20.3-10.6 \mathrm{bar}$

$p_{2}^{l}=6.1-10.0 \mathrm{bar}$

Lêngth $=18.7 \mathrm{~km}$

Cool-down time $=12.2$ days
Run 904

Near-end, refrigerator Scheme $B$

Far-end, $80 \mathrm{~K} \mathrm{LN}$ cooling

$P_{2}=15.2-6.8$ bar

$P_{2}^{1}=3.0-6.9 \mathrm{bar}$

Léngth $=14 \mathrm{~km}$

Cool-down time $=9.8$ days precooling

Run 627

Near-end, refrigerator Scheme $B$

Far-end, $80 \mathrm{~K} \mathrm{LN}$, cooling

$P_{1}=20.3-10.6^{2}$ bar

$P_{2}^{1}=6.1-9.9$ bar

Lêngth $=18.7 \mathrm{~km}$

Cool-down time $=12.7$ days

RUN 624

Near-end, refrigerator SCHEME A

Far-end, $80 \mathrm{~K} \mathrm{LN}_{2}$ cooling

$P_{1}=20.3-10.6^{2}$ bar

$P_{1}=6.1-9.9 \mathrm{bar}$

Léngth $=18.7 \mathrm{~km}$

Cool-down time $=23$ days

Run 529

Heat leak $=2 \times$ nominal value

Near-end, $10 \mathrm{~K}$ refrigerator

Far-end, Turboexpander with $80 \mathrm{~K} \mathrm{LN}_{2}$ precooling

$P_{3}=20.3-10.6$ bar

$P_{2}^{1}=6.1-9.9$ bar

Length $=18.7 \mathrm{~km}$

Cool-down time $=12.2$ days

Run 519

Co-current cool-down

Near-end, $10 \mathrm{~K}$ refrigerator

in $=1.0 \mathrm{~kg} / \mathrm{s}$

Length $=28 \mathrm{~km}$

Cool-down time $=3.8$ days

Run 505

Near-end, $10 \mathrm{~K}$ refrigerator

Far-end, turboexpander with $80 \mathrm{~K} \mathrm{LN}_{2}$ precooling

$P_{1}=20.3-10.6 \mathrm{bar}$

$\mathrm{P}^{\mathrm{l}}=6.1-10.0 \mathrm{bar}$

Léngth $=28 \mathrm{~km}$

Cool-down time $=38$ days 
Run 325

Near-end, $10 \mathrm{~K}$ refrigerator

Far-end, turboexpander with $65 \mathrm{~K} \mathrm{LN}_{2}$ precooling

$P_{1}=15.2-11.1$ bar

$\mathrm{p}_{2}^{1}=6.1-7.7$ bar

Length $=28 \mathrm{~km}$

Cool-down time $=90$ days

Run 321

Near-end, $10 \mathrm{~K}$ refrigerator

Far-end, turboexpander wi thout precooling

$P_{1}=15.2-11.1$ bar

$\mathrm{P}_{2}^{1}=6.1-7.7$ bar

Lêngth $=28 \mathrm{~km}$

Cool-down time $=170$ days

Run 319

Near-and, $10 \mathrm{~K}$ refrigerator

Far-end, turboexpander wi thout precooling

$P_{1}=15.2-10.1$ bar

$\mathrm{P}_{1}^{1}=6.1-8.0$ bar

Lèngth $=14 \mathrm{~km}$

Cool-down time $=17$ days

Run 314

Near-end, $10 \mathrm{~K}$ refrigerator

Far-end, turboexpander with $65 \mathrm{~K}$ precooling

$P_{1}=15.2-10.1$ bar

$\mathrm{P}_{2}^{1}=6.1-7.9$ bar

Lêngth $=14 \mathrm{~km}$

Cool-down tine $=10.1$ days

Run 313

Near-end, $10 \mathrm{~K}$ refrigerator

Far-end, turboexpander with $80 \mathrm{~K} \mathrm{LN}_{2}$ precooling

$P_{1}=15.2-10.1$ bar

$\mathrm{P}_{2}^{1}=6.1-8.0$ bar

Lêngth $=14 \mathrm{~km}$

Cool-down time $=11$ days

Run $312 b$

Near-end, $10 \mathrm{~K}$ refrigerator

Far-end, turboexpander with $80 \mathrm{~K} \mathrm{LN}_{2}$ precooling

$P_{1}=15.2-10.1$ bar

$P_{2}^{l}=6.1-7.5$ bar

Lêngth $=28 \mathrm{~km}$

Cool-down time $=84$ days

\section{Run 126}

Near-end, $10 \mathrm{~K}$ refrigerator

Far-end, turboexpander without precooling

$P_{1}=15.2-10.1 \mathrm{bar}$

$P_{2}^{1}=6.1-8.0$ bar

Lêngth $=28 \mathrm{~km}$

Cool-down time $=104$ days
Run 324

Near-end, $10 \mathrm{~K}$ refrigerator

Far-end, turboexpander with $65 \mathrm{~K} \mathrm{LN}_{2}$ precooling

$P_{1}=15.2-9.1$ bar

$\mathrm{p}_{2}^{l}=6.1-8.2 \mathrm{bar}$

Lêngth $=28 \mathrm{~km}$

Cool-down time $=69$ days

Run 320

Near-end, $10 \mathrm{~K}$ refrigerator

Far-end, turboexpander without precooling

$P_{1}=15.2-9.1$ bar

$P_{2}^{1}=6.1-8.2$ bar

Léngth $=28 \mathrm{~km}$

Cool-down time $=131$ days

Run 313

Near-end, $10 \mathrm{~K}$ refrigerator

Far-end, turboexpander with $65 \mathrm{~K} \mathrm{LN}_{2}$ precooling

$P_{1}=15.2-10.1 \mathrm{bar}$

$P_{2}^{l}=6.1-7.3$ bar

Lêngth $=23 \mathrm{~km}$

Cool-down time $=77$ days

Run 314b

Near-end, $10 \mathrm{~K}$ refrigerator

Far-end, turboexpander with $65 \mathrm{~K} \mathrm{LN}_{2}$ precooling

$P_{1}=15.2-10.1 \mathrm{bar}$

$\mathrm{P}_{2}^{l}=0.1-7.9$ bar

Lêngth $=18.7 \mathrm{~km}$

Cool-down time $=22.5$ days

Run 312

Near-end, $10 \mathrm{~K}$ refrigerator

Far-end, turboexpander with $80 \mathrm{~K} \mathrm{LN}_{2}$ precooling

$P_{1}=15.2-10.1$ bar

$\mathrm{P}_{1}^{1}=6.1-8.1$ bar

Lêngth $=18.7 \mathrm{~km}$

Cool-down time $=26$ days

Run 225

Near-end, $10 \mathrm{~K}$ refrigerator

Far-end, $10 \mathrm{~K}$ refrigerator

$P_{1}=15.2-10.1$ bar

$\mathrm{P}_{2}^{1}=6.1-7.7$ bar

Lèngth $=14 \mathrm{~km}$

Cool-down time $=7.9$ days 


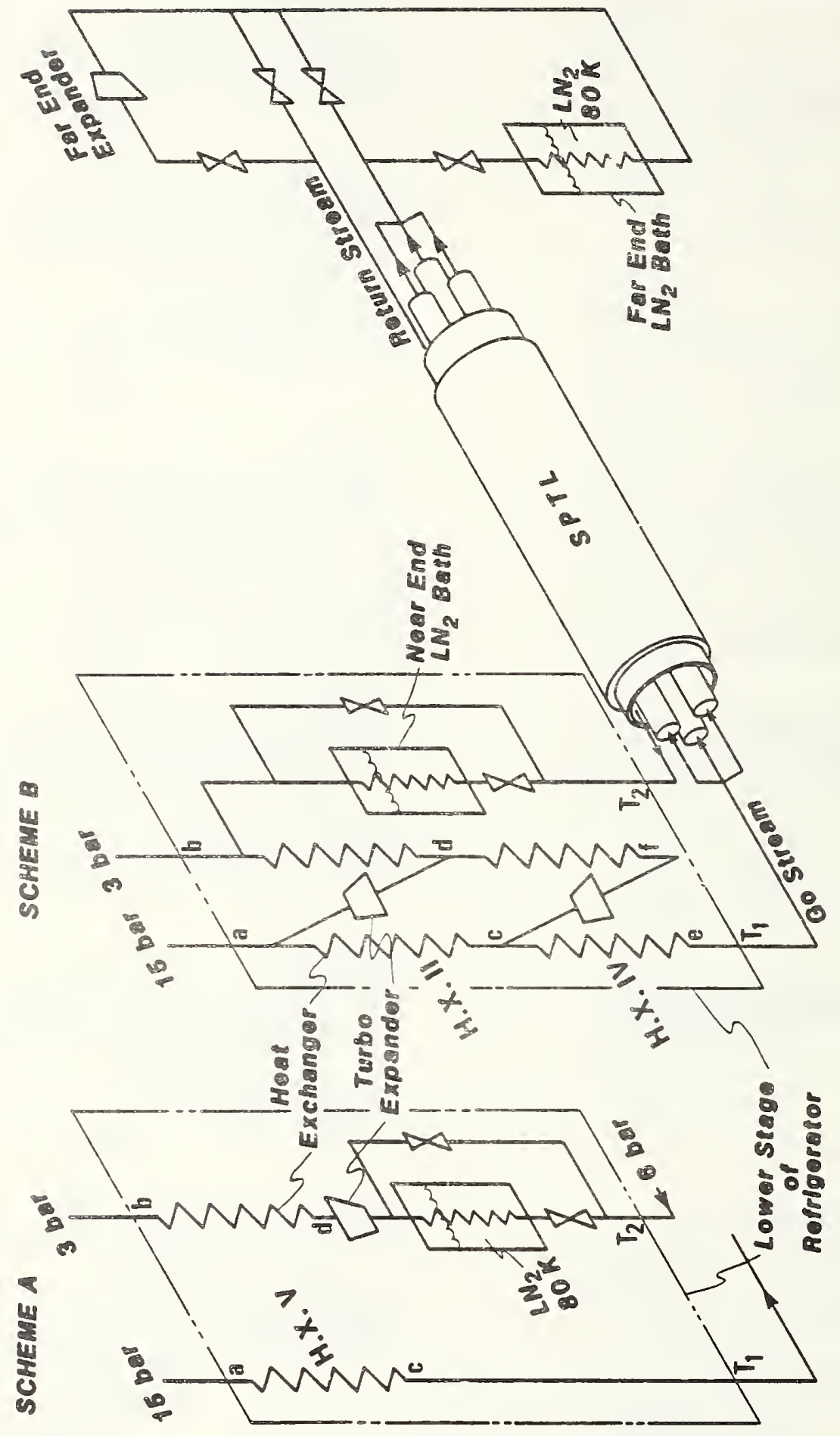

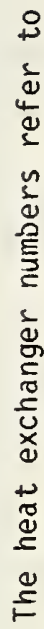

$\frac{5}{4}$

过

은

\%

o

¿

등

$\frac{1}{8}$

प?

苍

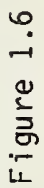




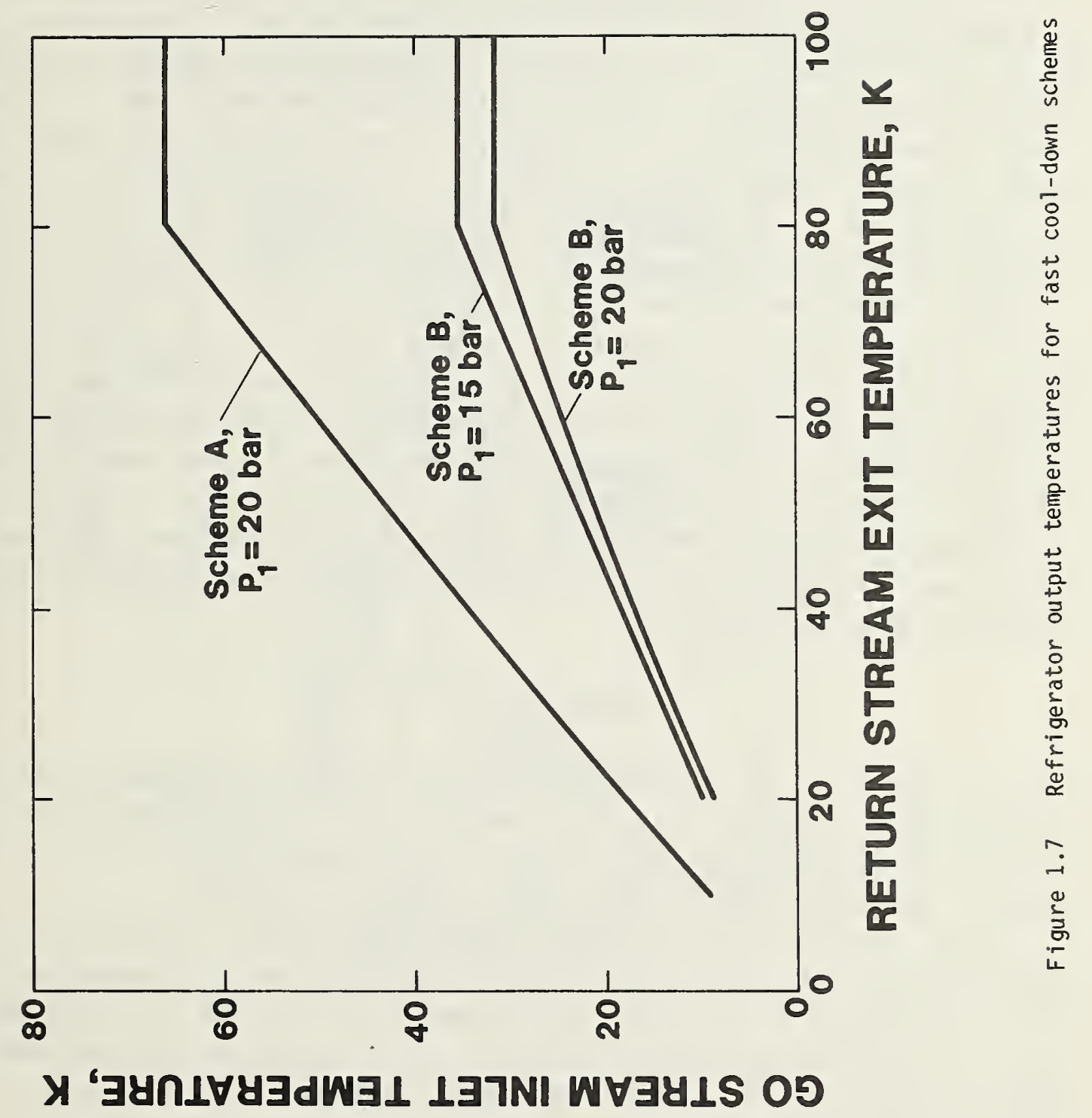


$T_{a}=80 \mathrm{~K}$, whichever is less. Knowing $T_{a}, T_{d}$, and the heat exchanger effectiveness, the heat exchanger is completely specified and $T_{C}\left(T_{1}\right)$ is obtained by iteration. That is, a value of $T_{b}$ is assumed and then the effectiveness is calculated using real helium properties. If the calculated effectiveness does not agree with the assumed effectiveness, then a new value of $T_{b}$ is chosen and the calculation is repeated. The choice of $T_{a}=2 T_{2}$ is not completely arbitrary, since this is approximately the condition for normal operation.

The evaluation of scheme $B$ proceeds in an analogous fashion. The return stream exit temperature is cooled by the $L_{2}$ bath wher $T_{2}$ is greater than $80 \mathrm{~K}$. Temperature $T_{b}$, the heat exchanger effectiveness, the expander efficiency, $P_{a}$ and $P_{d}$ determine the upper heat exchanger operating condition. A value of $T_{a}$ is estimated, and $T_{d}$ is then calculated from $F_{a}, P_{d}$, and the expander efficiency. Temperature $T_{c}$ and the heat exchanger effectiveness are then computed. If the calculated effectiveness does not agree with the chosen value, then a new value of $T_{a}$ is assumed and the calculation is repeated. The lower heat exchanger is now completely determined since $T_{C}, T_{d}, P_{C}, P_{f}$ and the expander efficiency are known.

Scheme $A$ reduces the cool-down time from 28 days (run 605) to 23 days (run 624) for a $18.7 \mathrm{~km}$ length, and Scheme B reduces it to 12.7 days (run 627) or 11.6 days (run 627b). The shorter time for run $627 \mathrm{~b}$ results from the 3.0 bar return stream exit pressure. These times for Scheme B are close to those for constant temperature near-end refrigeration (run 506) and about $50 \%$ greater than the 7.9 days attained for counter-flow cool-down using constant temperature refrigerators at both ends (run 225).

Although we explored 24 different c00l-down cases, there still remain many more conditions of possible interest. We may extrapolate these results over a limited range by using our previous analytical results $[3]$.

$$
t_{c d} \sim l^{m}(\bar{p} \Delta p)^{n}
$$

where $m=3$ and $n=-1$. A somewhat more accurate extrapolation uses exponents evaluated from the numerical results. In figure 1.8 and 1.9 , we plot cool-down time versus length and the product of average pressure $\bar{p}$ times the pressure drop $\Delta p$ for the up-stream. The exponents evaluated from these figures are $m=2.8$ and $n=-0.85$.

Warm-up (run 1015) takes considerably longer than cool-down. For this case it required 23 days to warm the mid-point to $257 \mathrm{~K}$, and we estimate approximately 30 days to warm to $0^{\circ} \mathrm{C}$. This aysmmetry in the warm-up and cool-down times is not due to any fundamental difference in these processes. Rather it is due to the strong temperature dependence of the cable and enclosure heat capacities. During warm-up the heat capacity is largest during the final stages when both the flow and the temperature difference between the go and return streams are at a minimum.

The slow warm-up is not necessarily as disadvantageous as it might seem, however, because the time reported in table 1.2 refers only to the mid-point temperature for a $14 \mathrm{~km}$ length. Repairs requiring warm-up would probably not be made at the mid-point, and a section of cable exposed for repair would quickly warm-up without counter-flow circulation of the helium. 


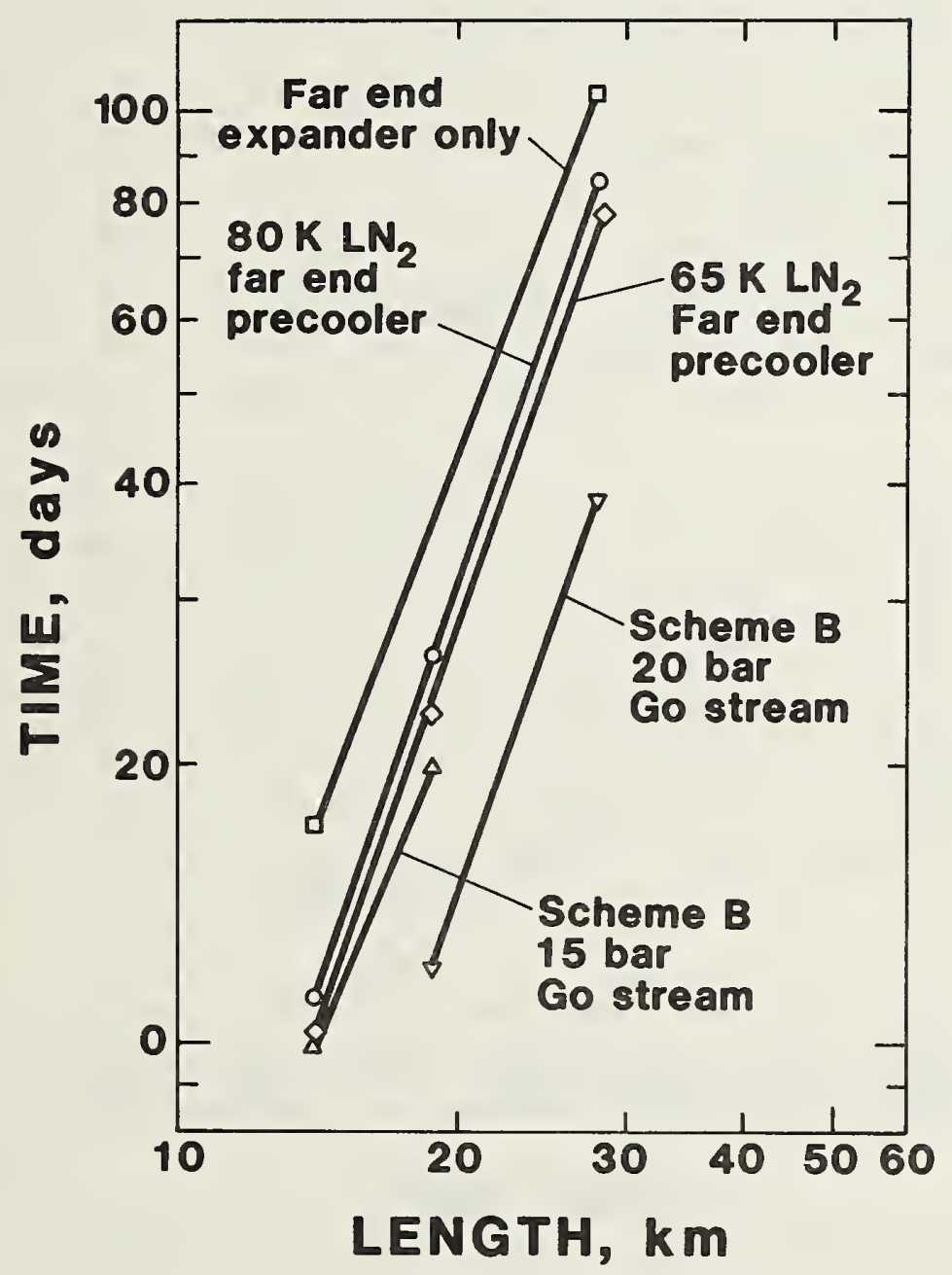

Figure 1.8 Cool-down times as a function of length for several cooling arrangements 


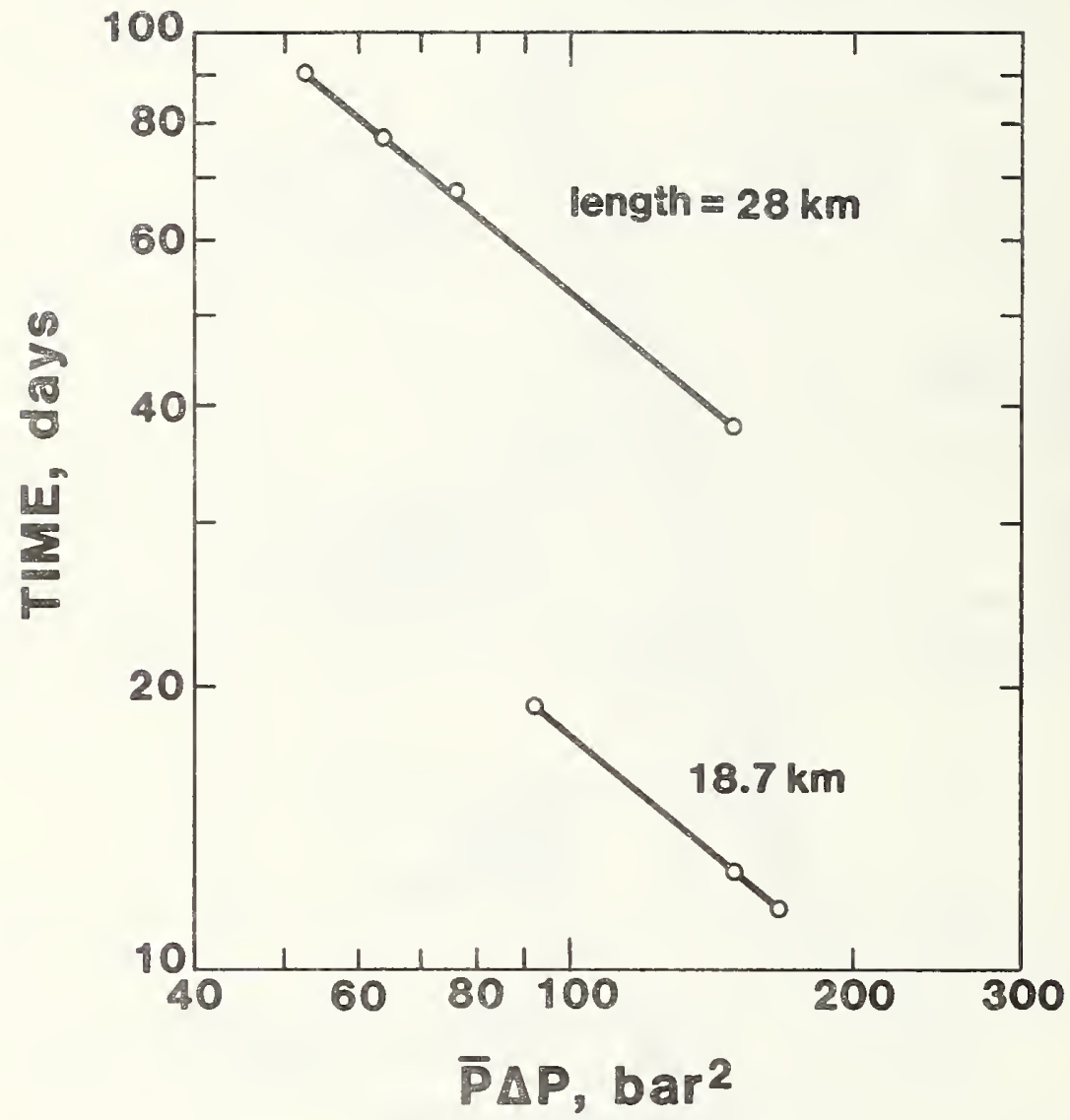

Figuer 1.9 Cool-down times versus the product of the average go-steam pressure and pressure drop. The $28 \mathrm{~km}$ curve is for a $10 \mathrm{~K}$ near-end refrigerator, and a $65 \mathrm{~K}$ far-end precooler. The $18.7 \mathrm{~km}$ curve is for Scheme B with an $80 \mathrm{~K}$ far-end precooler. 


\subsection{Fast Cool-Down Prototype}

A prototype of a fast cool-down SPTL refrigerator for the PECo system is the configuration assumed for run 904. Figure 1.10 shows this arrangement which uses the Scheme B refrigerator at the near-end and liquid nitrogen cooling at the far-end. A 10 day cool-down time is computed for a $14 \mathrm{~km}$ cable length. Note that Scheme B is essentially the same arrangement as the midportion of the standard refrigerator (figure 1.3) proposed for steady state cooling of the SPTL. The principle modification is the addition of the $\mathrm{LN}_{2}$ cooler. The go-stream inlet pressure is 15.2 bar and the cooling channel length is $14 \mathrm{~km}$. The liquid nitrogen baths are bypassed once the temperature for the associated helium stream falls below $80 \mathrm{~K}$, and the far-end expander is bypassed during the entire cool-down so that all the available pressure drop may be used to increase the mass flow rate.

Although Scheme B is a conceptually simplified version of the refrigerator shown in figure 1.3, there is no practical requirement for the elimination of heat exchangers III and $v$. The elimination of these heat exchangers is merely a device to simply the analysis. Thus the practical implementation of Scheme B would be the refrigeration of figure 1.3 with an added $\mathrm{LN}_{2}$ cooler.

The operating conditions are given in figure 1.11 which shows the liquid nitrogen consumption rates, helium inlet temperatures to the $\mathrm{LN}_{2}$ precooling and go-stream helium mass flow rate. The cool-down history for the entire length is given in figure 1.12.

The total liquid nitrogen consuption at the far-end is $4.5(10)^{5} \&\left(1.19(10)^{5}\right.$ gal $)$ without counter-flow heat exchange to the nitrogen boil off gas and $3.68(10)^{5} \ell\left(0.97(10)^{5}\right.$ gal) with counter-flow heat exchange. The near-end liquid nitrogen consumption is $0.95(10)^{5} \ell\left(.25(10)^{5} \mathrm{gal}\right)$. An example of a suitable far-end $\mathrm{LN}_{2}$ precooler would be a coil of tubing $50 \mathrm{~m}$ long by $10 \mathrm{~cm}$ i.d. tubing immersed in a $\mathrm{LN}_{2}$ dewar.

\subsection{Summary}

The work presented in this report demonstrates that the original refrigerator scheme for the PECo SPTL (designed for steady state operating conditions) must be modified if acceptable cool-down times are to be achieved. Without modification a 104 day cool-down time is expected.

Two principal modifications are required if short cool-down times are to be obtained. The refrigerator spacing must be reduced from $56 \mathrm{~km}$ to $28 \mathrm{~km}$ (14 km cooling channel length), and liquid nitrogen cooling must be used both at the refrigerator and the far-end. With those modifications the computed cool-down time for a $14 \mathrm{~km}$ cable length is 10 days. For fastest cool-down, the far-end expander is by-passed so that all the available pressure drop is used to increase the mass flow rate in the cooling channel.

Finally, we note that the trends of these computer calculations agree well with our previous numerical work so that (1.13) may be used to extrapolate the results of the 24 cool-down cases studied here. 


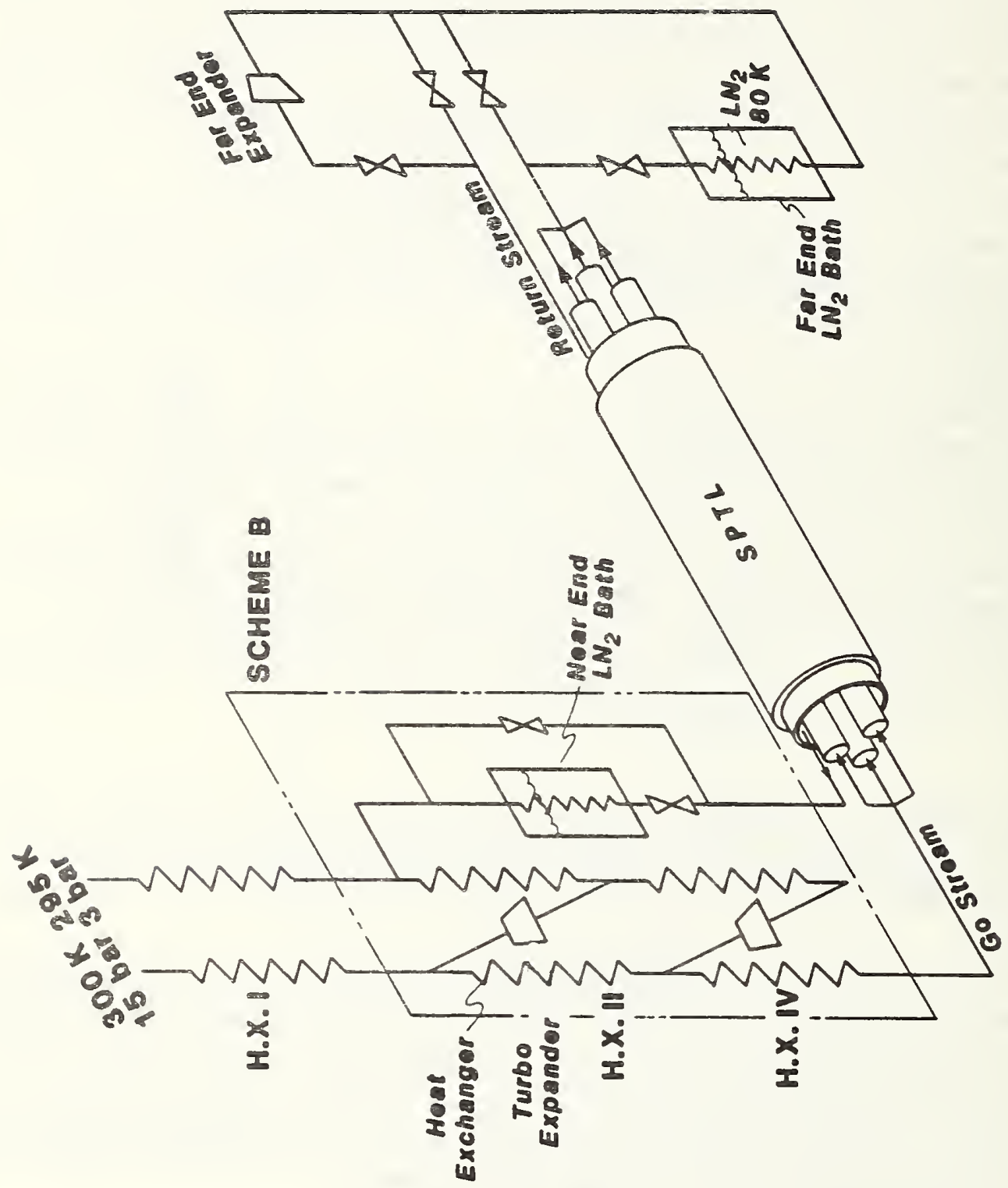

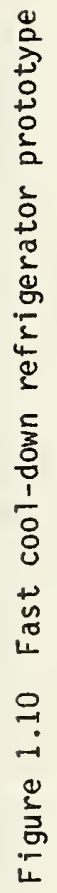




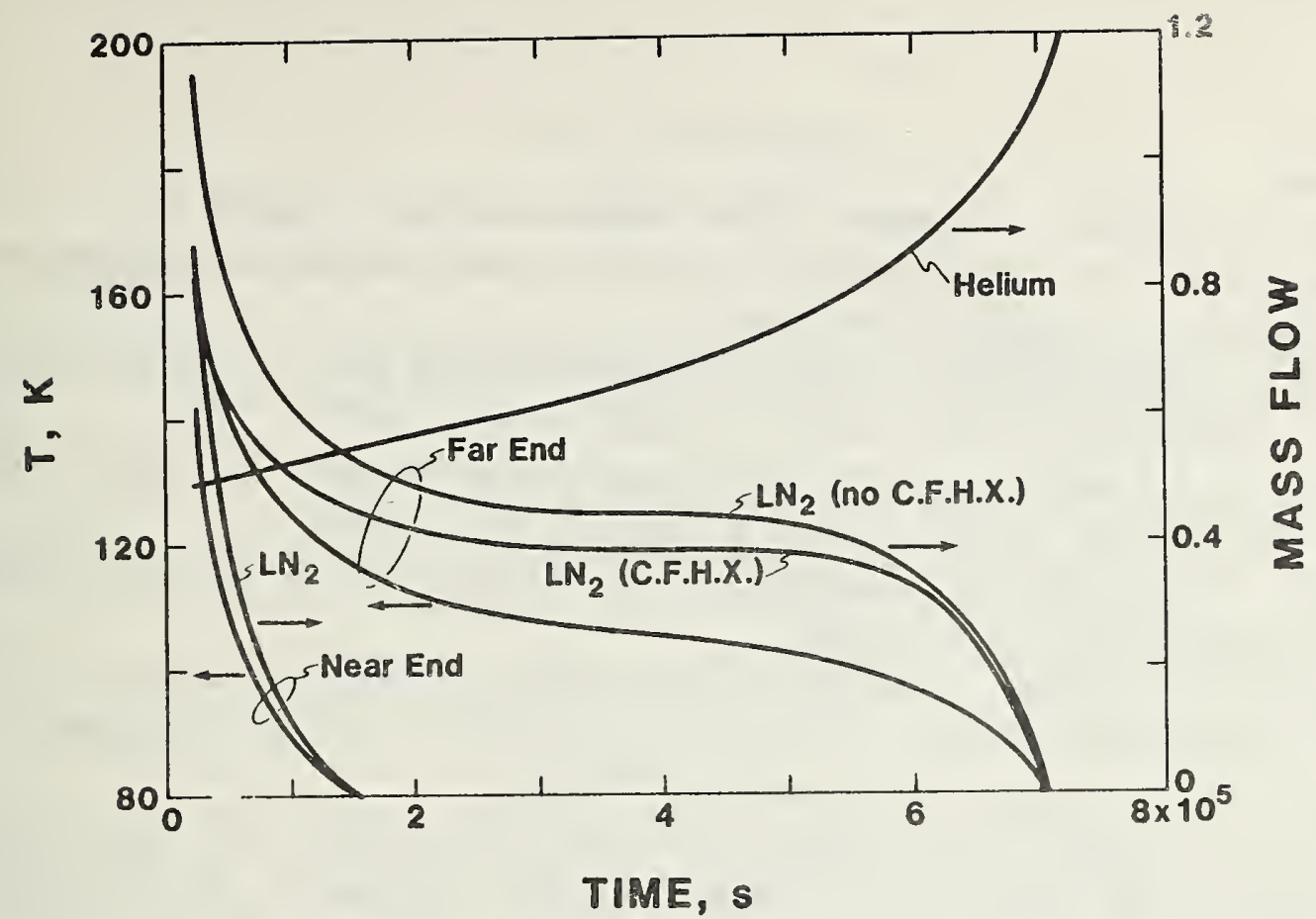

Figure 1.11 Liquid nitrogen consumption and operating conditions for fast cool-down prototype

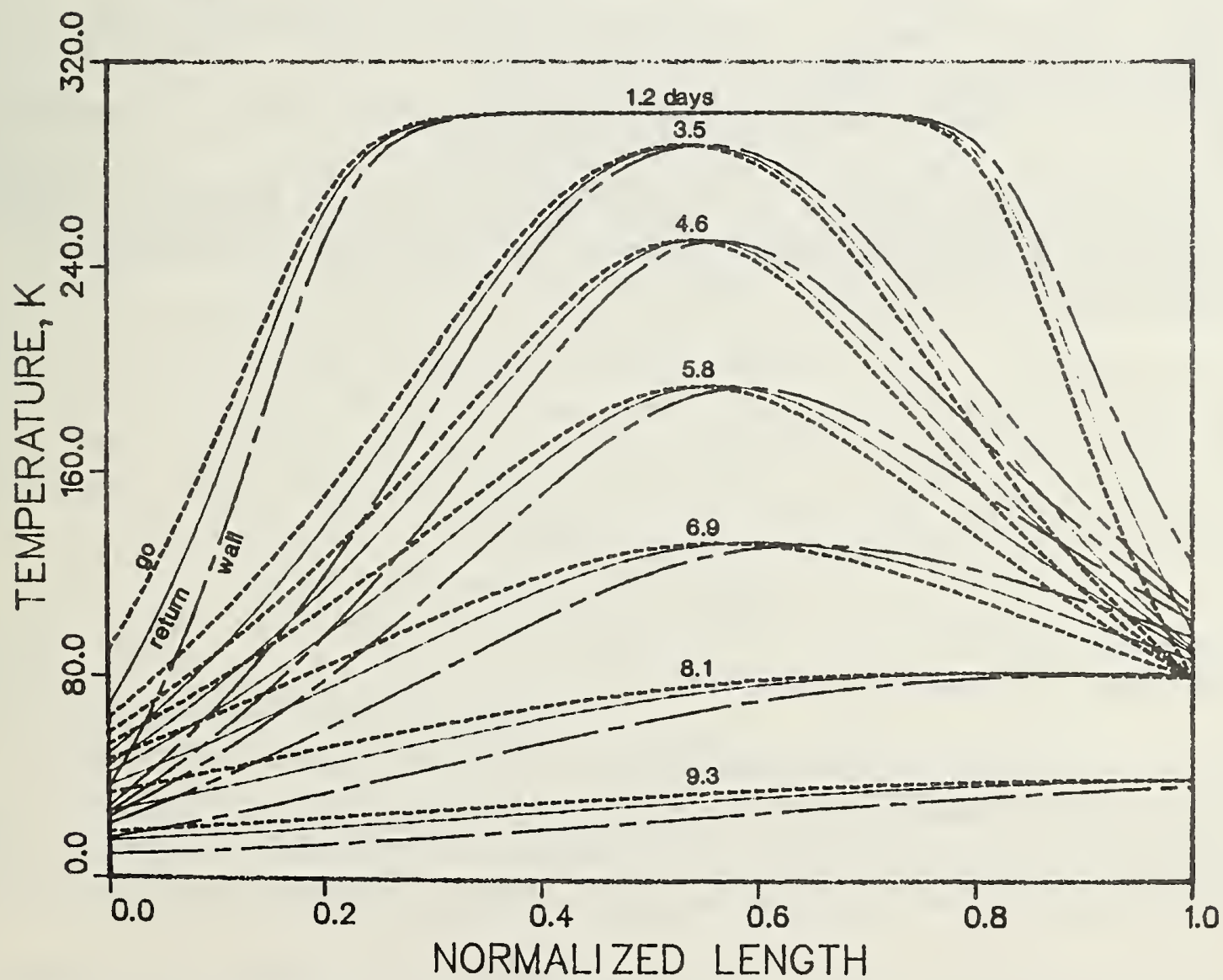

Figure 1.12 Cool-down history for SPTL with fast cool-down refrigerator prototype, run 904. 


\subsection{References}

[1] Daney, D. E., Cool-down of cryogenic power transmission lines, Progress in Refrigeration Science and Technology, Proceedings of XVth International Congress of Refrigeration, Venice (Italy), 1979 (1980).

[2] Daney, D. E., Helium research in support of superconducting power transmission, Annual Report, NBSIR 79-1618, National Bureau of Standards (U.S.) (1979).

[3] Daney, D. E., Helium research in support of superconducting power transmission, Annual Report, NBSIR 80-1637, National Bureau of Standards (U.S.) (1980).

[4] Jones, M. C., Cool-down of superconducting power transmission lines with single phase helium, Cryogenics 20, 139-145 (1980).

[5] Evaluation of the economical and technological viability of various underground transmission systems for long feeds to urban load areas, Final Report, Department of Energy (U.S.), Report HCP/T-2055/1 (December 1977).

[6] Dean, J.W., and Jensen, J.E., Supercritical helium refrigeration for superconducting power transmission cable studies, Advances in Cryogenic Engineering, 21, Proceedings of 1975 Cryogenic Engineering Conference, Kingston, Ontario, Plenum Press, New York (1976).

[7] Morgan, G. H. and Jensen, J. E., Counter-flow cooling of a transmission line by supercritical helium, Cryogenics, 17, 259-267 (1977).

[8] McCarty, R. D., Thermodynamic properties of Helium 4 from 2 to $1500 \mathrm{~K}$ at pressures to 10(8) Pa, J. Phys. Chem. Ref. Data 2, 923-1041 (1973).

[9] Madsen, N.K., and Sincovec, R. F., General software for partial differential systems, in Numerical Methods for Differential Systems, L. Lapidus and W. E. Schiesser, ed. Academic Press, Inc., New York (1976). 


\subsection{HEAT-FLOW METERS}

(P. R. Ludtke)

\subsection{Introduction}

The feasibility of using heat-flow (thermal flux) meters on the outer surface of a cryogenic envelope as non-intrusive indicators of insulating vacuum degradation is the subject of this section.

A passive, non-intrusive indicator of the insulation quality has the desirable characteristics of allowing one to completely seal (weld) the vacuum enclosure and to forget about o-ring seal problems and human errors associated with instrusive type vacuum sensors and gauges. An external sensor becomes even more desirable if the transfer line is buried. With this in mind, an investigation was conducted to determine the feasibility of using heat-flow meters for this application.

One of the major concerns when using heat-flow meters underground is the magnitude of the thermal flux within the earth compared to the thermal flux of interest. Near the surface of the earth, the thermal gradient is affected by four different mechanisms:

a. The surface of the earth is continuously heated by thermal energy from the earth's

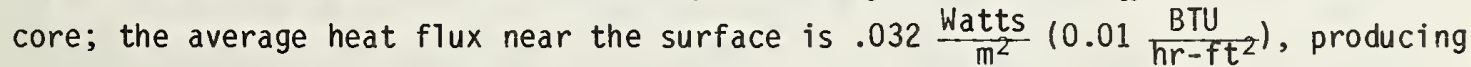
a geothermal gradient of about $1^{\circ} \mathrm{C} / 24.4$ meters $\left(1^{\circ} \mathrm{C} / 80\right.$ feet). This constant source of energy is quite smal1 compared to the average energy from surface normal solar radiation of $915 \mathrm{~W} / \mathrm{m}^{2}\left(290 \frac{\mathrm{BTU}}{\mathrm{hr}_{\mathrm{ft}} \mathrm{ft}^{2}}\right)$ on a clear day.

b. The varying thermal energy at the earth's surface due to diurnal radiation is another consideration. It has been established that variations of the surface temperature due to heating by day and cooling at night do not penetrate below the surface more than $90-120 \mathrm{~cm}$ (3-4 feet) [2].

c. The annual or seasonal temperature changes near the surface of the earth are of a larger magnitude; the changes from the cold of winter to the heat of sumner may affect the temperature of the earth to a depth of 18-21 meters (60-70 feet) [2].

d. Local weather conditions usually do not affect the thermal gradient at a depth of 1.5 meters, however, it will be shown that the moisture from a heavy snow melt will disturb a stable thermal gradient at this depth.

Thus, thermal energy from three of the above mechanisms contribute to the net thermal gradient at a depth of 1.5 meters (axis of the pipe-section); the effects of diurnal solar radiation become negligible at this depth.

During the first phase of the project, four different pairs of commercially available meters were mounted on a short pipe section, tested and calibrated under controlled conditions. The meters were found to have good sensitivity, and the calibrations were linear and repeatable with small deviations. Details of the work in phase 1 are given in NBSIR 80-1637 [1].

During the seond phase of the investigation, the pipe section was buried for an eleven month field test; the results of the undergound testing are reported here. 


\subsection{Pipe Section and Meter Assembly}

A section of steel pipe $(61 \mathrm{~cm}$ long $\times 50.8 \mathrm{~cm} 0 . D . \times 0.64 \mathrm{~cm}$ wall) was selected to simulate a cryogenic envelope. Eight heat-flow meters from four different manufacturers were epoxied to the outside of the pipe. The meters will be referred to as "A", "B", "C", and "D" pairs to eliminate bias toward any one manufacturer. Table 2.1 1ists the characteristics of each meter.

Six of the meters have flat surfaces, and the other two have surfaces contoured to fit the outer surface of the pipe. Copper adapters with one side flat and the other side curved were machined from high purity copper. The adapters were designed such that the curved surface area was equal to the flat surface area of the heat-flow meters. A moderately highthermal-conductivity epoxy was used to bond the adapters and meters to the steel pipe. Sensors from each pair were mounted $180^{\circ}$ from each other on a circumferential centerline, equidistant from each end of the pipe. The outer surface of the pipe was divided by four quadrant lines parallel to the pipe axis. Two sensors were placed near each quadrant line; the edge of each sensor was $2 \mathrm{~cm}$ from the quadrant line.

Thin stainless steel strip heaters were bonded to the inside of the pipesection to provide a source of energy for calibration and testing. The stainless steel strips were $59.7 \mathrm{~cm}$ long $\times 2.46 \mathrm{~cm}$ wide $\times .005 \mathrm{~cm}$ thick, wired in series, and bonded to the pipe inner surface with RTV silicone. The inside of the pipe was filled with pour-type polyurethane foam, and the ends were squared-off and hermetically sealed with fiberglass caps. A thin coat of RTV silicone coating was applied onto the sensors with sandwich construction for an additional hermetic seal.

\subsection{Field Burial, Pipe Assembly}

The pipe assembly was buried to center-1ine depth of 1.5 meters and backfilled with clean, dry mortar sand. Type $E$ thermocouples were placed in the sand during backfill to determine the thermal gradient of the earth in the vicinity of the pipe section. A crosssection showing the burial configuration is shown in figure 2.1. The pipe was laid in the ground horizontally, with the quadrant lines in the vertical and horizontal planes. This configuration places 2 sensors on the bottom of the pipe, 2 on the top, and 4 on the sides. A photograph of the pipe placement in the hole just prior to backfilling with sand is shown in figure 2.2 .

The pipe was buried 7 meters from the side of the laboratory; wiring from the sensors and earth thermocouples was routed inside the building over a length of approximately 30 meters using pair shielded cables. The heat-flow meter signals were wired directly into a multi-range, multi-point recorder, and the thermocouple signals were connected to a solidstate ice reference, and then to the multi-point recorder. DC power leads were connected to the internal strip heaters, providing the option of heating the inside of the pipe. 
Table 2.1 Heat-Flow Meter Characteristics

\begin{tabular}{|c|c|c|c|c|c|}
\hline Brand & $\begin{array}{l}\text { Size } \\
(\mathrm{cm})\end{array}$ & $\begin{array}{c}\text { Controured } \\
\text { Surface }\end{array}$ & $\begin{array}{c}\text { Manufacturer's } \\
\text { Sensitivity } \\
\frac{\mu \mathrm{N}}{\mathrm{cm}^{2}-\mathrm{mV}}\end{array}$ & $\begin{array}{c}\text { Type of } \\
\text { Contruction }\end{array}$ & $\begin{array}{l}\text { Type of } \\
\text { Sensor }\end{array}$ \\
\hline A & $11.4 \times 11.4 \times .48$ & No & 300 & $\begin{array}{l}\text { Integral, Epoxy } \\
\text { Glass }\end{array}$ & Thermopile \\
\hline B & $5.08 \times 15.2 \times .64$ & Yes & 135 & $\begin{array}{l}\text { Integral, Diallyl } \\
\text { Phthalate }\end{array}$ & Thermopile \\
\hline C & $15.2 \times 15.2 \times .47$ & No & 113 & $\begin{array}{l}\text { Sandwich Copper- } \\
\text { polyimide }\end{array}$ & Solid state \\
\hline D & $5.08 \times 5.08 \times .25$ & No & 160 & $\begin{array}{l}\text { Sandwich Aluminum- } \\
\text { phenolic }\end{array}$ & Solid state \\
\hline
\end{tabular}




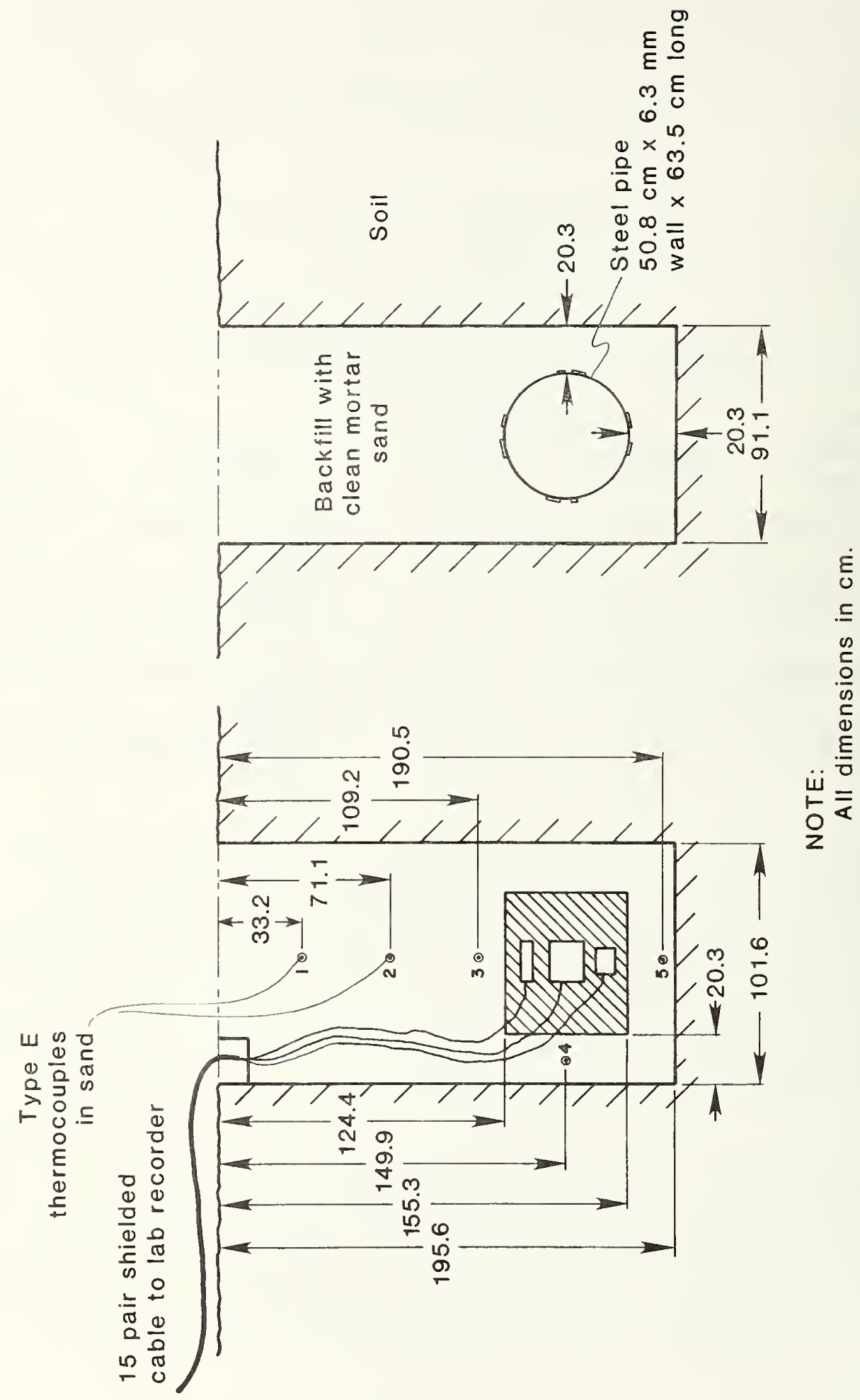

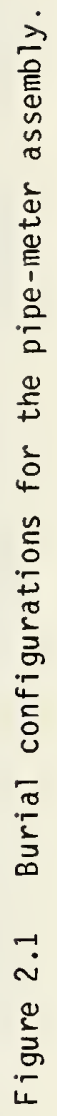




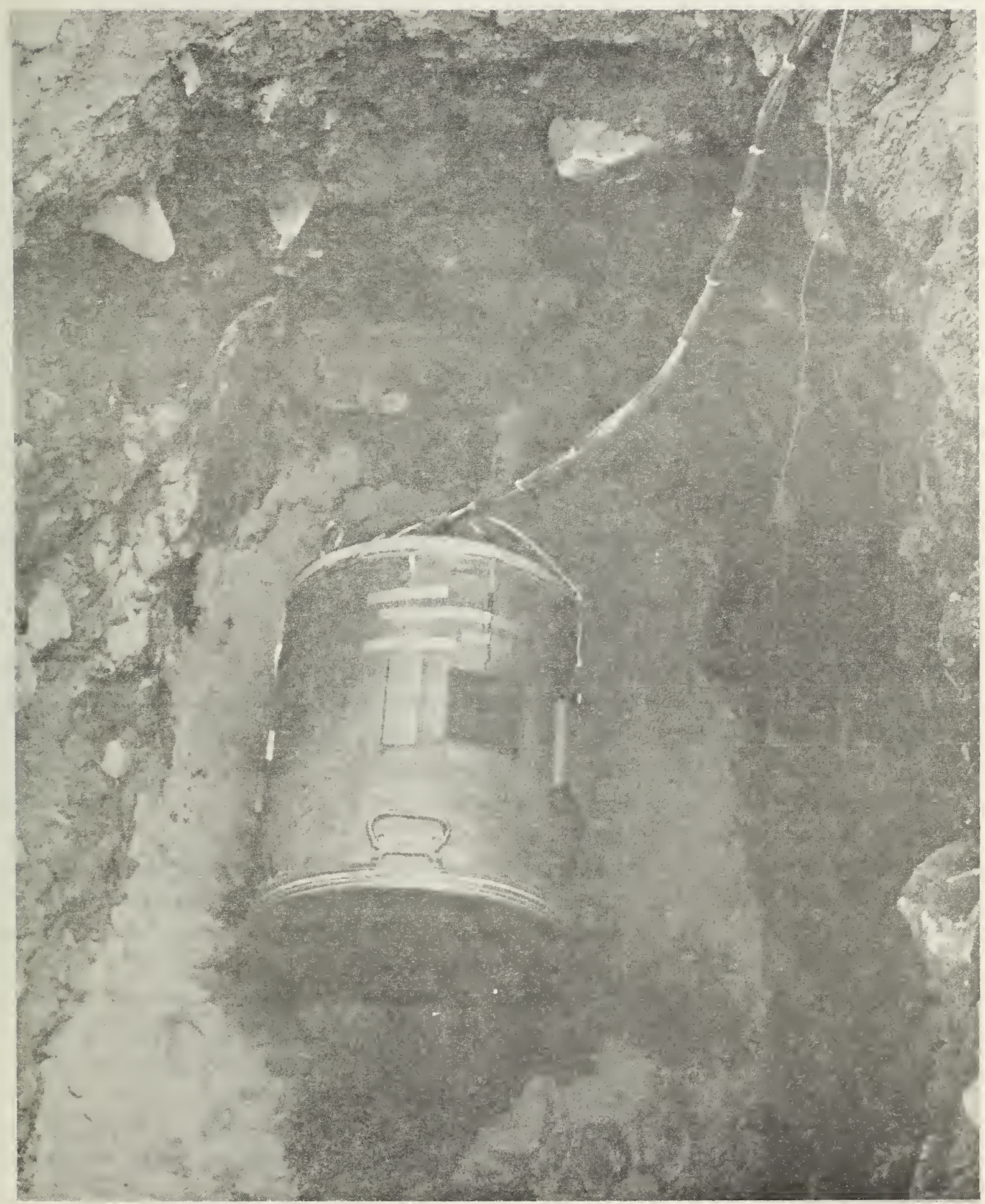

Figure 2.2 Photograph of pipe before back-filling. 


\subsection{Test Sequence}

A chronological listing of the test sequence is given below:

$$
\begin{aligned}
& 8-20-79 \\
& 8-20-79 \text { to } 9-16-79 \\
& 9-16-79 \text { to } 1-3-80
\end{aligned}
$$

$1-22-80$

$2-29-80$

$3-14-80$

$5-30-80$

$7-29-80$

$8-4-30$

$8-11-80$
Buried the pipe section

Allowed the burial area to assume an equilibrium temperature

Started data recording of earth thermocouples and heatflow meter emf. Zerr power input to pipe section. Just observed the heatflow meter emf due to the thermal gradient of the earth.

Applied $275 \mathrm{mi}$ power to the pipe section. This is the power necessary to generate a heat flux of $28 \mu \mathrm{w} / \mathrm{cm}^{2}$-the predicted heat flux of the BNL-3 cryogenic envelope. Maintained this power level until 1-22-80.

Increased the internal power to $1380 \mathrm{~mW}$; this power level produces a heat flux 5 times the predicted level. This power level was maintained until 2-29-80.

Decreased the power into the pipe section from 1380 to 275 $\mathrm{mW}$; this decreases the heat flux from 5 times to 1 times the predicted value. This power level was maintained unti1 3-14-80.

Increased the power level from 275 to $824 \mathrm{~mW}$; a change in heat flux from predicted to 3 times predicted value. This power level was maintained until 5-30-80.

Decreased the power level from $824 \mathrm{mw}$ to zero. Observed the heat-flow meter emf's at zero power level from 5-30-80 unti 7 7-29-80.

Excavated the pipe section to a horizontal position above ground with the axis $76 \mathrm{~cm}$ above the surface. Observed the heat-fiow meter emf's with zero internal power and no cover over the pipe section.

A completely shaded enclosure consisting of one layer of double aluminized Mylar of $635 \mu \mathrm{m}$ thickness was built around the pipe section. The heat-flow meter emf, with zero power input, was observed until 8-11-80. Terminated the test.

\subsection{Test Results}

The pipe section was buried for eleven months (8-29-79 to 7-29-80). During that period, two of the heat-flow meters malfunctioned -- the first 28 days after the burial and the second after approximately 7 months. Upon excavation both of the "0" meters were seriously delaminated, apparently due to moisture. The other meters were all intact and working properly. 
The vertical temperature profile of the sand backfill during the test period is shown in figure 2.3. The significant aspects of the earth temperature plots are:

a. The upper thermocouple $(33 \mathrm{~cm}$ below the surface) is quite susceptible to local weather conditions, whereas the lower thermocouple (below the pipe section) is affected very little by day-to-day or local weather patterns.

b. The vertical temperature difference across the pipe holds fairly steady (at $4^{\circ} \mathrm{r}$,) during the winter montins, decreases to zero in April, and starts to reverse in May.

c. Changes in electrical power into the pipe section have negligible effect on the thermocouples above and below the pipe section.

d. A fast heavy snow melt at the surface, caused by Chinook winds peculiar to Boulder, colorado results in water near $0^{\circ} \mathrm{C}$ seeping down through the sand the altering the temperature gradient near the pipe. This occurred on 12-4-79 and 1-13-80. The sand temperature directly above and below the pipe section decreased by 1.0 to $1.2^{\circ} \mathrm{C}$.

e. The temperature excursion of the thermocouple $20 \mathrm{~cm}$ below the pipe section varied from a $10 \mathrm{w}$ of $7^{\circ} \mathrm{C}$ in February to a high of $24^{\circ} \mathrm{C}$ in July.

\subsection{Field Performance of the "A" and "B" Pair of Heat-Flow Meters}

Meter pairs "A" and "B" were mounted just off the vertical plane of the pipe section, as shown in figure 2.4. The behavior of the " $A$ " and " $B$ " pairs was nearly the same; however, the "B" pair is approximately 2.2 times more sensitive than the "A" pair. After examining the meter emf's for the period from 9-15-79 to 1-30-80 (at zero power level), it became evident that the meters were experiencing a thermal field of considerable magnitude. As illustrated by figure 2.4, the soil heat flux does not bypass the pipe. Instead it enters the pipe wall at the bottom and exits at the top. In doing so the heat flux passes through the top and bottom meters in opposite directions (the meters are wired to give a positive signal for a radial outward heat $f(u x)$ and produces the mirror image signals of figure 2.4. The thermal conductance of the pipe wall (thermal conductivity tines the cross section area) is the same order of magnitude as the thermal conductance of the soil, so the heat flux measured by the "A" and "B" meter pairs is also of the same order as tine soil heat flux -- even though they are mounted on the pipe surface.

After establishing the behavior of the system with zero heater input, the heatar was turned on $(1-3-80)$ to simulate the predicted heat flux of BNL-3 cryogenic envelop: (?3 $\mu \mathrm{W} / \mathrm{cm}^{2}$ heat flux or $275 \mathrm{~mW}$ total power). During the remainder of the test the power was stepped up and down by as much as five times the nominal value to datermine the minimum detectable change in heat flux.

An interesting but disturbing aspect of the data plots is the effect of a heavy snow melt on the heat-flow meter emf. Heavy snow melts occurred on 12-1-79 and 1-13-80, and on both occasions, the meter signals experienced large excursions of about twice tine previous 


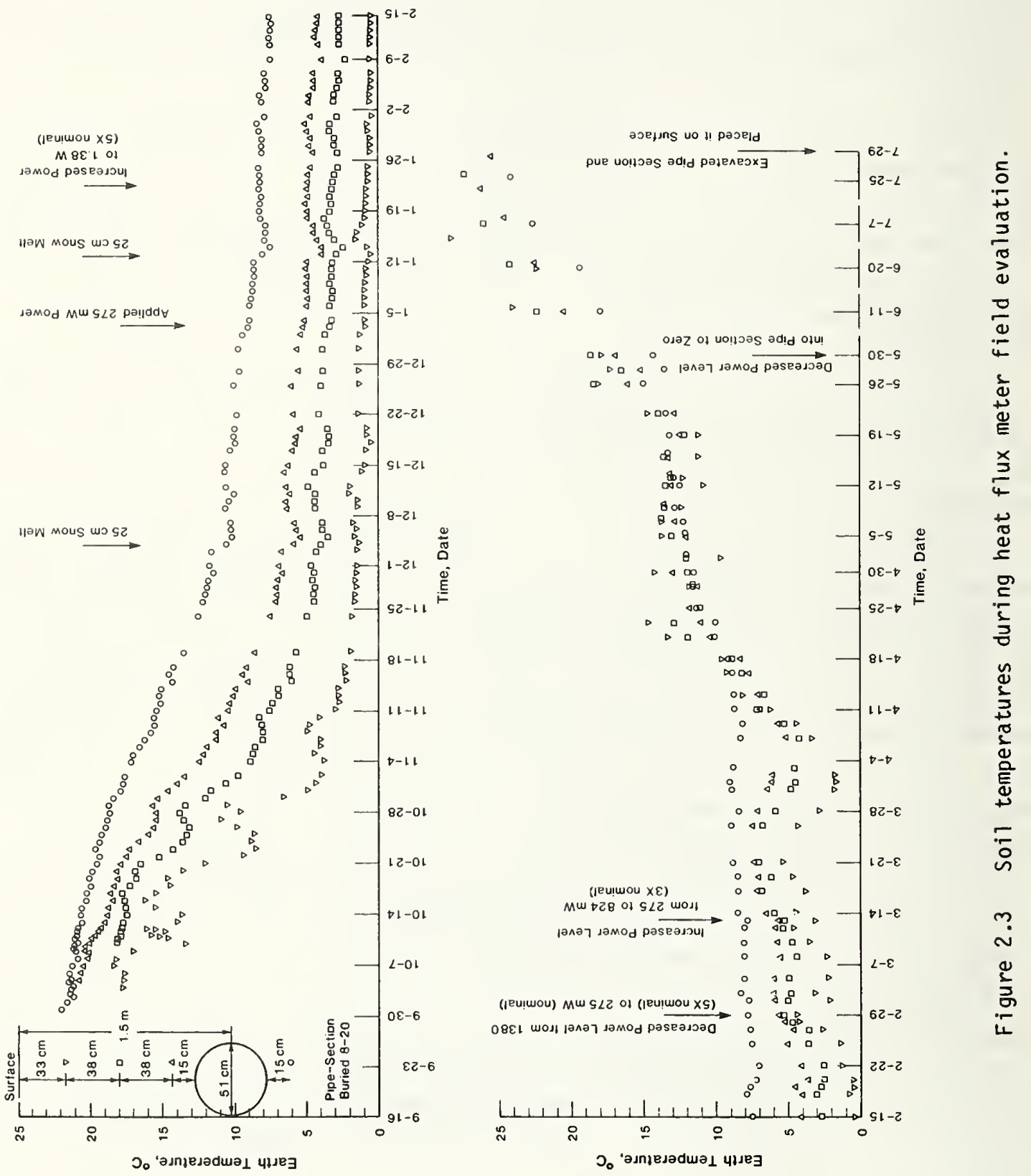



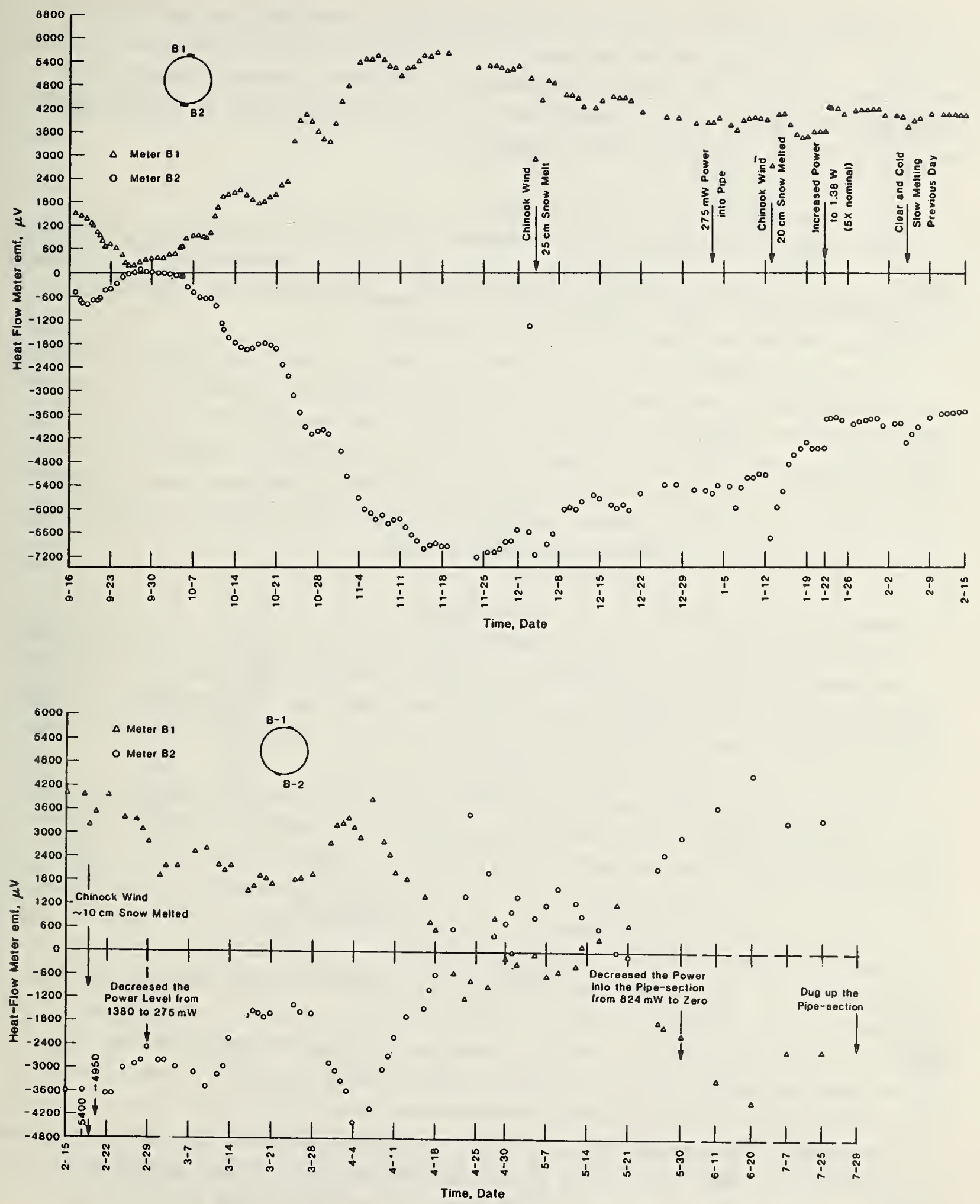

Figure 2.4 Field response of meters $B 1$ and $B 2$. 
The data indicate that it is not possible to clearly distinguish a gradual change in heat flux of even 5 times the nominal value for individual vertically mounted meters such as the "B" pair. However, the mirror image behavior for the pair of sensors suggests that adding the output from a pair of sensors would cancel much of the effect of the soil heat flux. This idea is discussed in detail in section 2.8.

\subsection{Field Performance of the "C" Pair of Meters}

The " $C$ " pair of heat-flow meters were mounted just off the horizontal plane of the pipe section. The " $\mathrm{C}$ " meters were the largest of $a 11$; the center of the meters was $9.6 \mathrm{~cm}$ from the horizontal plane and $180^{\circ}$ from each other. The companion pair of "D" meters near the horizontal plane malfunctioned during the burial period.

The individual plots of "C1" and "C2" emf's, figure 2.5, were in most aspects about the same as the plots for the " $A$ " and " $B$ " meter pairs even though the " $C$ " meters were a mirror image of each other, especially with zero power input. The same perturbations occurred during the heavy snow melts as with meters "A" and "B", (signal shifts approximately twice current values). A step power increase of 5 times predicted value gives a very distinct shift in signal level from each meter, but again this would not be nearly as distinct if this increased heat flux occurred over a period of time.

\subsection{Summation of the emf from the "C" Pair of Meters}

After observing the mirror image signals from each pair of sensors, it became apparent that the best way to minimize the effect of the earth's thermal gradient would be to arithmetically sum the emf from a meter pair. The " $C$ " meter pair near the sides of the pipe section was selected, since this pair is less susceptible to the earth's radial thermal gradient because of its nearly horizontal orientation.

Summing the pair signals has the net effect of minimizing the output due to a varying external thermal gradient, and of doubling the emf due to an increase in thermal flux through the pipe wal1. The emf sum from the meters "C1" and "C2" were plotted as shown in figure 2.6. The net effect of summing the enf's is easily illustrated by considering the period from 9-16-79 to 12-1-79. Meter "C1" had an excursion of $2000 \mu \mathrm{V}$ and meter "C2" had an excursion of $1900 \mu \vee$, whereas for the same period, the sum of "C1" + "C2" gives an excursion of $500 \mu \mathrm{V}$. Also, compare the effect of a step power increase. When the power was increased from 275 to $1380 \mathrm{~mW}$ on 1-22-80, "C1" changed $-710,1 \mathrm{~V}$ and "C2" changed -850, $\mathrm{V}$ whereas the sum of " $\mathrm{C} 1 "+{ }^{\prime \prime} \mathrm{C} 2 "=-1560 \mu \mathrm{V}$. Thus, the technique of summing the emf from a pair of heat-flow meters results in a signal change of twice the value for one sensor. It also gives a sizable cancelling effect of the emf due to external thermal fields.

In looking at the response of " $\mathrm{C} 1$ " + " $\mathrm{C} 2$ " to step power changes, the summed signal from a step increase in power from 1 times to 5 times predicted value is much inore distinct. Similarly, a significant decrease in signal level was experienced when the power was decreased the same amount on 3-1-80. Changes in power by a factor of 3 are not as perceivable, and could be masked by the daily variations if the thermal flux increased over a period of several days. However, if averages for several weeks are considered, changes of 

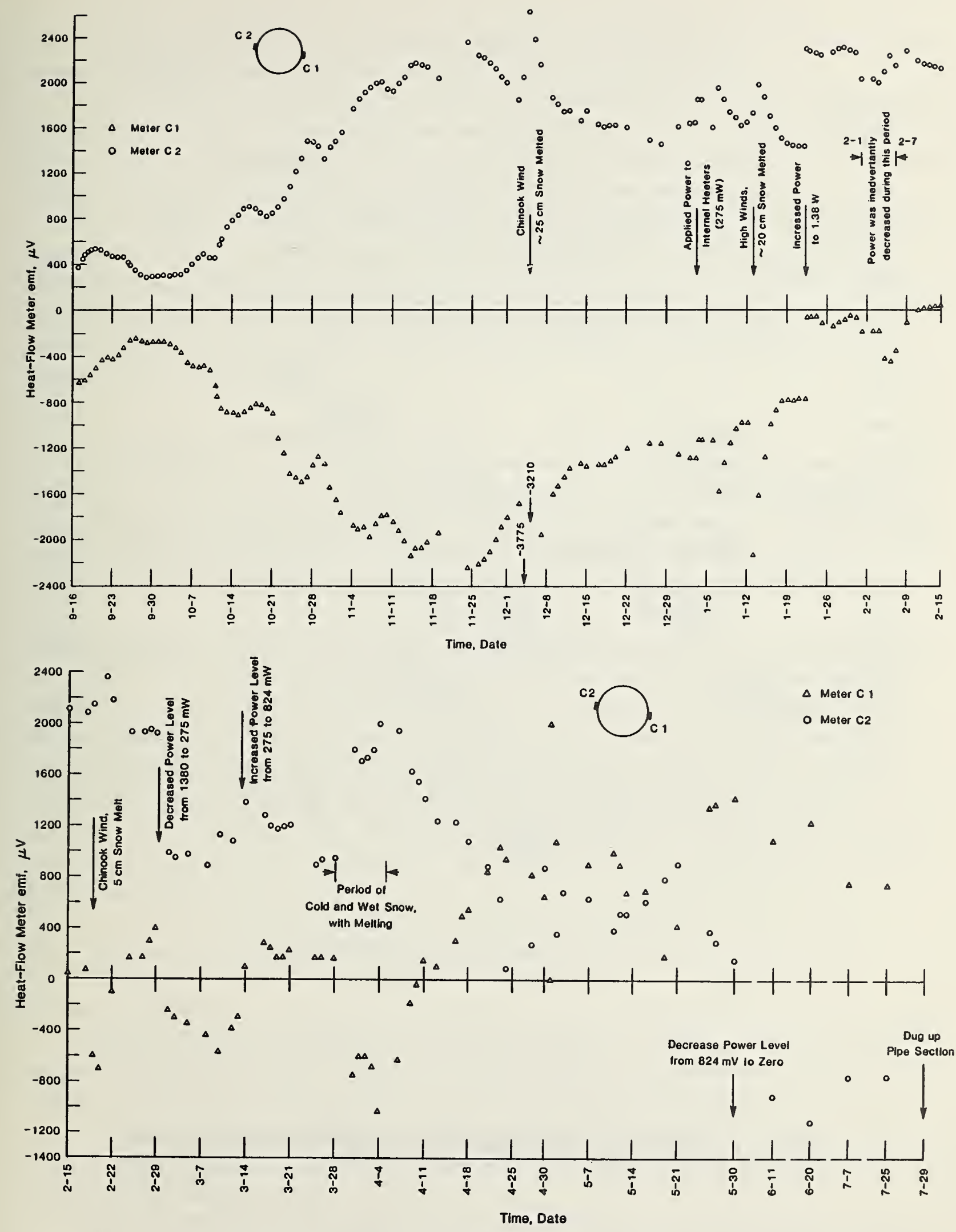

Figure 2.5 Field response of meters $\mathrm{C} 1$ and $\mathrm{C} 2$. 

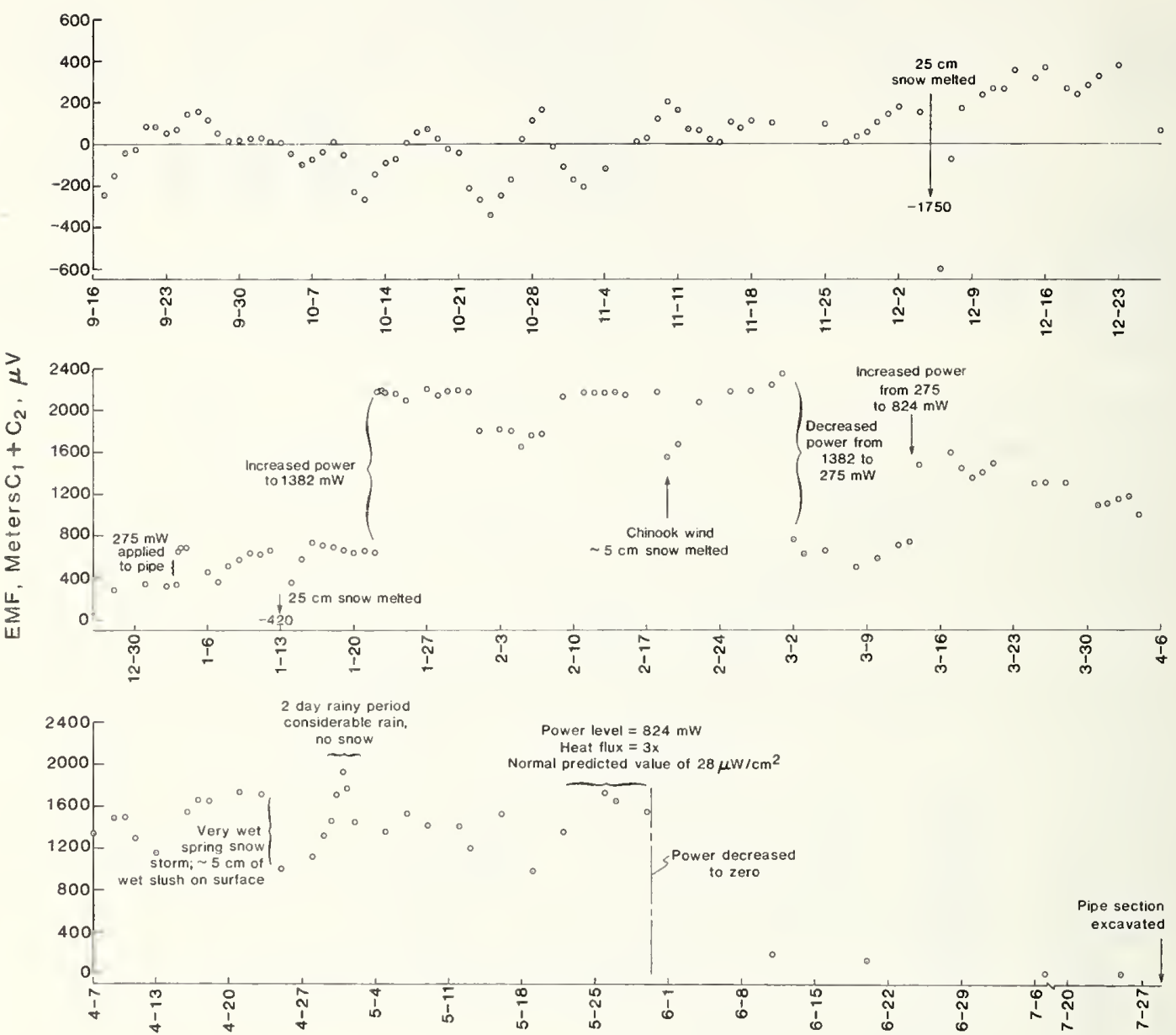

DATE

Figure 2.6 Effect of summing signals of horizontally opposed sensors. 
one or two times the nominal heat flux are detectable. The summing technique does not decrease the perturbations in meter signals when a heavy snow melt occurs.

The technique of summing the emf from all six functional meters was also investigated, but this was not nearly as well behaved as the plot of "C1" + "C2". The sum of the six heat-flow meters ranged from $+700 \mu$ Volts to $1700 \mu \mathrm{V}$ for the period 9-16-79 to 1-4-80. This is considerably more than the $500 \mu \nu$ for $(" \mathrm{C} 1 "+$ "C2") for the same period.

In the summary, it appears feasible that a pair (or several pairs) of heat-flow meters mounted on the sides of an undergound cryogenic envelope could be used as a insulation degradation sensor for thermal flux increase on the order of once or twice nominal values. In any field application one should bear in mind that the meters are very sensitive to extreme weather conditions capable of disturbing the thermal gradient of the earth near the pipe such as a heavy snow melt.

\subsection{Time Response of the Heat-Flow Meters}

The response time of the heat-flow meters was monitored during the step power increase to the pipe section. Figure 2.7 shows the time response of the " $C$ " meter pair to a power increase from 275 to $1380 \mathrm{~mW}$ (predicted to 5 times predicted heat flux). The time constant is 18 minutes. So in spite of the large mass of the steel pipe section, the time response is more than adequate for sensing vacuum degradation over a relatively short time period.

\subsection{Comparison of a Meter Thermocouple to an Earth Thermocouple During a Snow-Melt Period} After observing the snow melt perturbations, we looked more closely at thermocouple temperatures of the earth and meters. Figure 2.8 is a plot of the temperature of meter "D1" and of the sand backfill at the pipe section axis. The temperatures are the same prior to and after snow melt, but during the snow melt, the $0^{\circ} \mathrm{C}$ water from the surface seeps down through the sand and decreases the sand temperature at the pipe axis $1.4^{\circ} \mathrm{C}$ below that of the meter on the pipe section. Thus the meters are experiencing a $1.4^{\circ} \mathrm{C}$ temperature change at the outer surface which is responsible for the large signal perturbations occurring during heavy snow melts.

\subsection{Performance of the Heat-Flow Meters Above Ground}

\subsubsection{Non-Shaded}

The pipe section was excavated on 7-29-80 and placed on a wooden stand with the pipe axis $75 \mathrm{~cm}$ above the surface. Sensors "D1" and "D2" were both inoperative and badly delaminated, evidently due to moisture in the earth during the burial period.

The emf's from the meter pairs "A", "B", and "C", were monitored (with zero power input) for several days to determine the magnitude of the spurious thermal energy subjected to a pipe section above ground.

A plot of emf from the " $C$ " pair of sensors on the side of the pipe section is shown in figure 2.9. This plot is typical for all three pair of sensors. The variation in sensor emf during the (non-daylight) hours is considerably less than the variation during the 


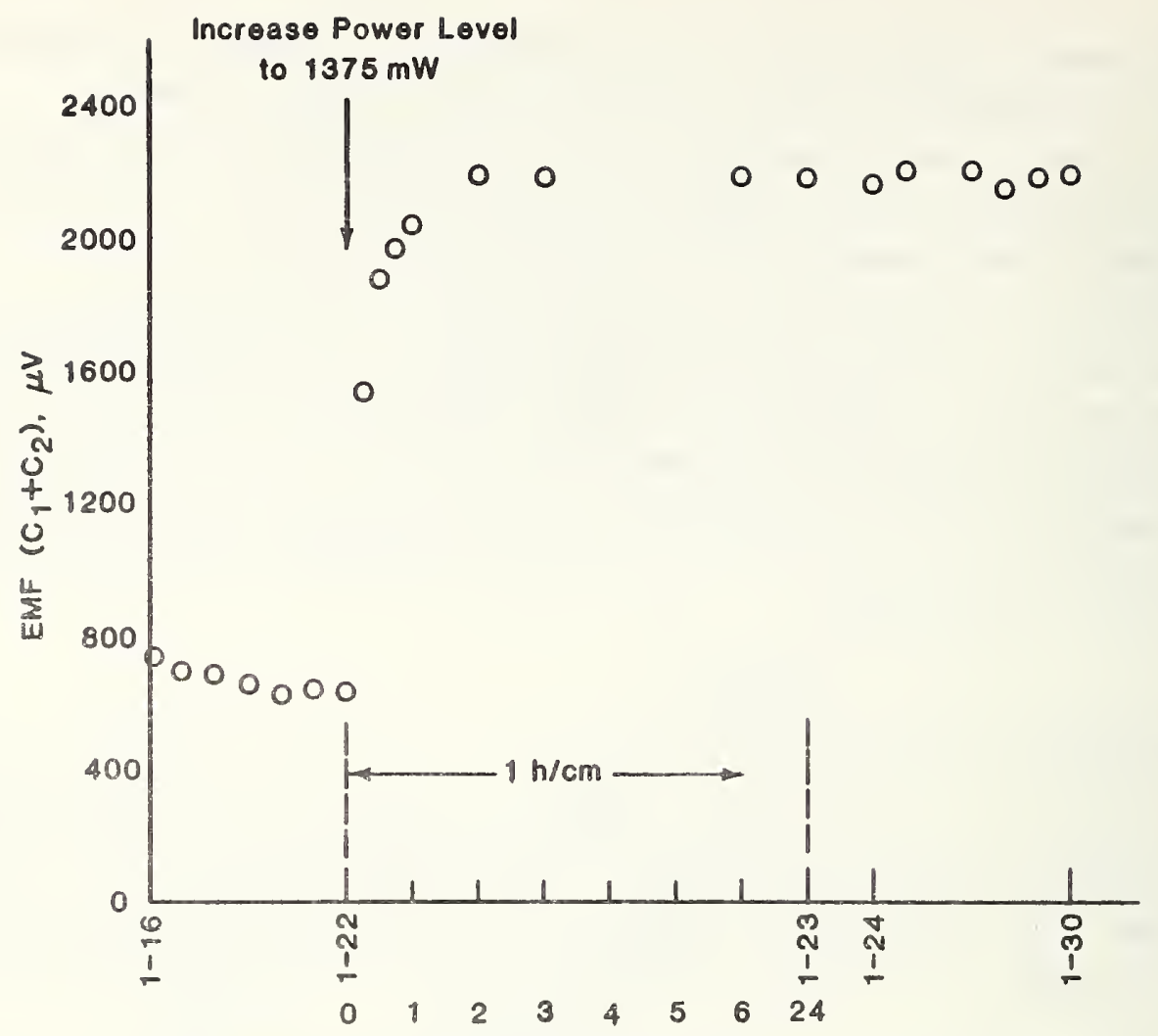

Figuer 2.7 Transient response of meters $\mathrm{C} 1$ and $\mathrm{C} 2$.

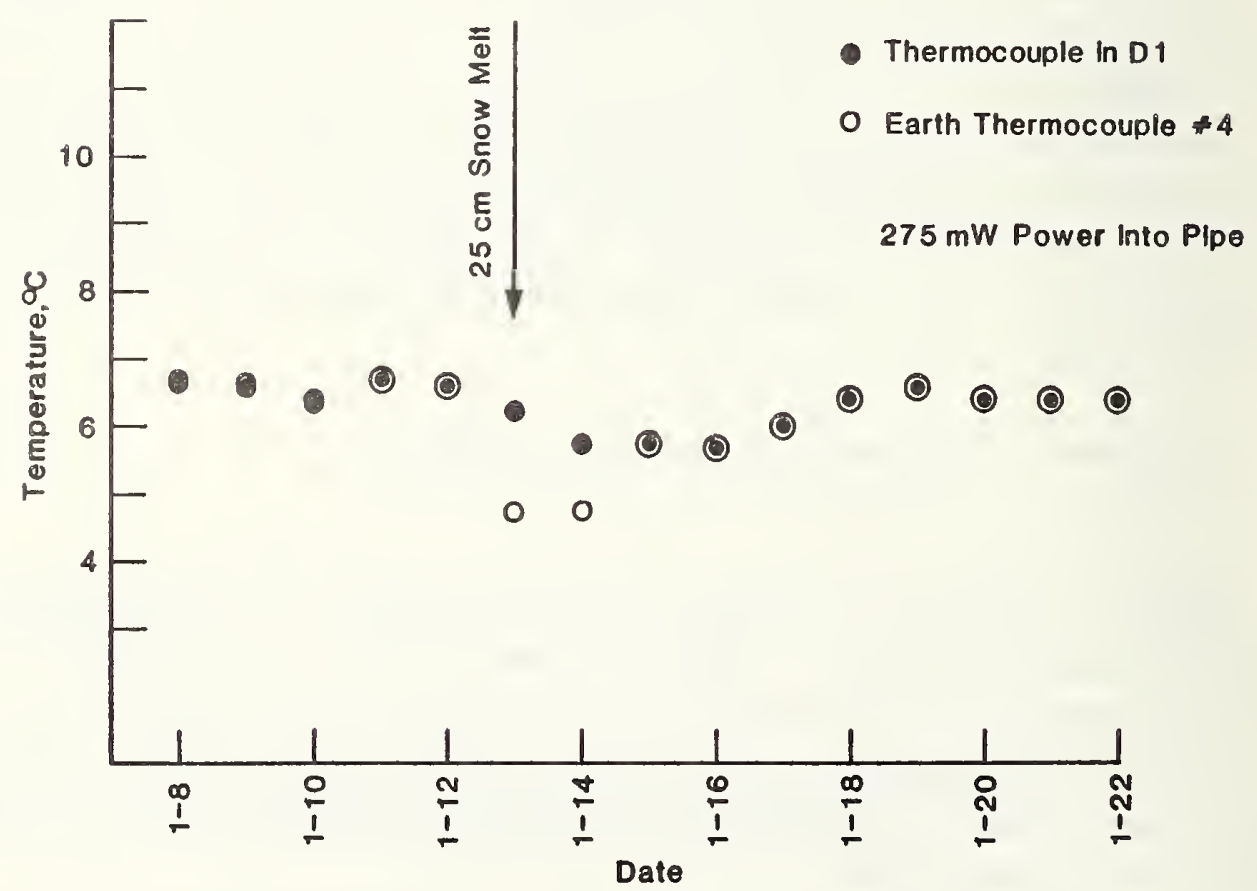

Figure 2.8 Comparison of earth and sensor temperatures during a snow melt. 


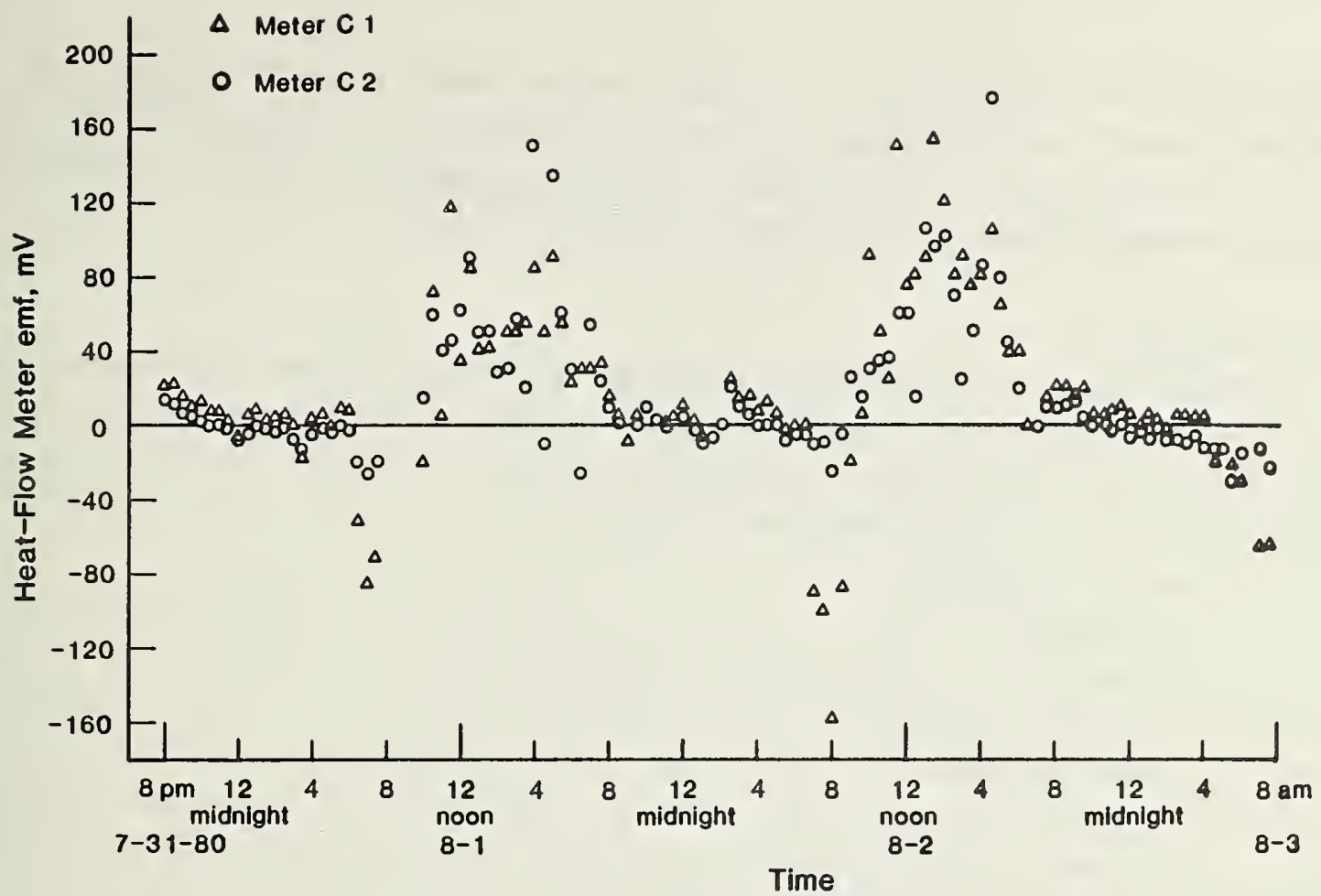

Figure 2.9 Above ground response of meters $\mathrm{C} 1$ and $\mathrm{C} 2$ - unshaded arrangement

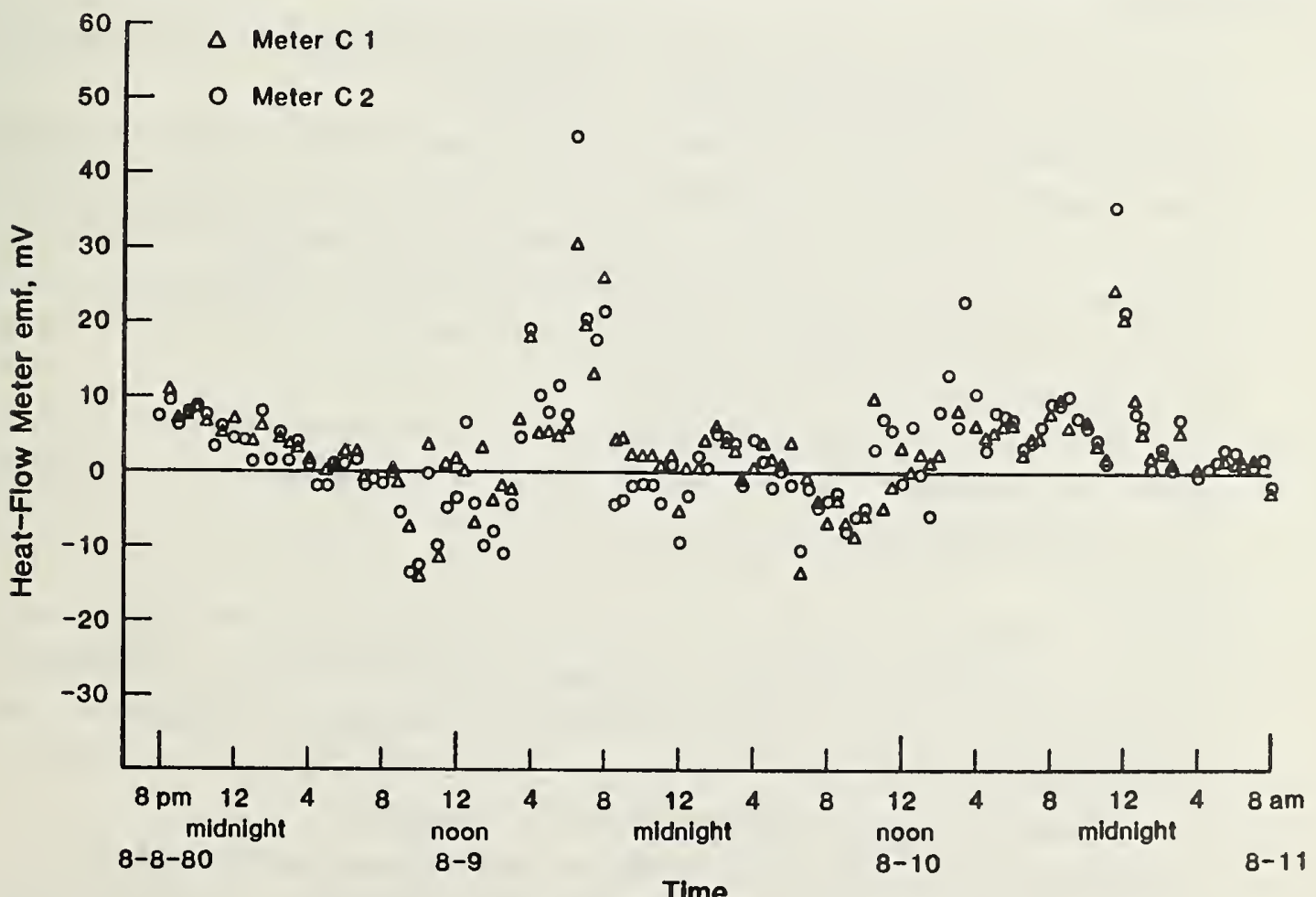

Figure 2.10 Above ground reponse of meters C1 and C2 - shaded arrangement. 
daylight hours when the pipe section is subject to the radiant energy of the sun. The variation of the "B" and "C" pairs of sensors was approximately $\pm 100 \mathrm{mV}$ during the day, and approximately $20 \mathrm{mV}$ during the night. For a predicted sensor emf of $250 \mu \mathrm{V}$, the above variations give noise to signal ratios of 400 and 80 respectively.

\subsubsection{Shaded Cover}

Because of the large variations in sensor emf during the daylight hours, a shade was placed almost completely around the pipe section in order to decrease the amount of solar radiation to the heat-flow meters. The shade consisted of one layer of $635 \mu \mathrm{m}$ thick double aTuminized Mylar. Once again, the power input was zero. The emf from the "c" pair of sensors is shown in figure 2.10.

The shade decreased the sensor variation by approximately an order of magnitude during the day. There was only a slight decrease in variation during the night. If we neglect the two spikes (due to short term weather disturbance) that occur in figure 2.10, and assign an approximate signal variation of $\pm 10 \mathrm{mV}$ to the sensors, we still obtain a noise to signal ratio of 40 for a predicted sensor emf of $250 \mu \mathrm{V}$. Thus, even with shading, and considering only the non-daylight variations, the noise to signal ratio is still excessive for detecting increases in envelope heat flux in the range up to 40 times predicted value.

\subsection{Conclusions}

a. All of the heat-flow meters tested had adequate sensitivity to sense changes in thermal fiux in the predicted range of $28 \mathrm{\mu w} / \mathrm{cm}^{2}$.

b. We experienced no physical problems with the meters of solid plastic construction. However, for meters of laminar construction, one pair failed completely, and the other pair suffered no damage during the 11 month undergound test period.

c. Both above and below ground, the meters are sensitive to anything that disturbs or changes the thermal gradient of the nearby surroundings; such as solar radiation above ground or moisture below ground.

d. The instrumentation necessary to measure the emf from the meters must be high quality and capable of measurements in the microvolt range. The instrumentation leads between the meters and the data acquisition equipment must be carefully shielded.

e. Heat-flow meters can be used as non-intrusive thermal flux meters for sensing insulation degradation within an undergound cryogenic envelope. The optimum configuration is to place a pair of meters $180^{\circ}$ opposed on a horizontal line thru the mid-section of the pipe. Our tests indicate that thermal flux increases of one or two times the nominal $28 \mu w / \mathrm{cm}^{2}$ should be detectable.

f. The successful use of heat-flow meters to sense insulation degradation in a cryogenic envelope outside, above ground, appears doubtful. Spurious thermal energy is significantly larger ( 40 times) than predicted heat leak through a high quality, vacuum insulated cryogenic envelope. 


\subsection{References}

[1] Daney, D. E., Helium Research in Support of Superconducting Power Transmission, NBSIR 80-1637, National Bureau of Standards (U.S.), 1980.

[2] Carslaw, H. S. and Jaeger, J. C., Conduction of Heat in Solids, 2nd Edition, Clarendon Press, 1959. 

